\title{
Dielectric, Thermal and Water Absorption Properties of Some EPDM/Flax Fiber Composites
}

\author{
Anton Airinei ${ }^{1, *}$, Mihai Asandulesa ${ }^{1, *(\mathbb{D}) \text {, Maria Daniela Stelescu }}{ }^{2}$, Niţă Tudorachi ${ }^{1}$, Nicusor Fifere ${ }^{1}$, \\ Adrian Bele ${ }^{1}$ (D) and Valentina Musteata ${ }^{1}$ \\ 1 Petru Poni Institute of Macromolecular Chemistry, 41A Grigore Ghica Voda Alley, 700487 Iasi, Romania; \\ ntudor@icmpp.ro (N.T.); fifere.nicusor@icmpp.ro (N.F.); bele.adrian@icmpp.ro (A.B.); \\ valentina.musteata@icmpp.ro (V.M.) \\ 2 National Research and Development Institute for Textile and Leather, Leather and Footwear Institute, \\ 93 Ion Minulescu Street, 031215 Bucharest, Romania; maria.stelescu@icpi.ro \\ * Correspondence: airineia@icmpp.ro (A.A.); asandulesa.mihai@icmpp.ro (M.A.)
}

check for updates

Citation: Airinei, A.; Asandulesa, M.; Stelescu, M.D.; Tudorachi, N.; Fifere, N.; Bele, A.; Musteata, V. Dielectric, Thermal and Water Absorption Properties of Some EPDM/Flax Fiber Composites. Polymers 2021, 13, 2555. https://doi.org/10.3390/ polym13152555

Academic Editor: Francisco Javier Espinach Orús

Received: 14 July 2021

Accepted: 30 July 2021

Published: 31 July 2021

Publisher's Note: MDPI stays neutral with regard to jurisdictional claims in published maps and institutional affiliations.

Copyright: (c) 2021 by the authors. Licensee MDPI, Basel, Switzerland. This article is an open access article distributed under the terms and conditions of the Creative Commons Attribution (CC BY) license (https:// creativecommons.org/licenses/by/ $4.0 /)$.

\begin{abstract}
This paper deals with the dielectric and sorption properties of some flax fiber-reinforced ethylene-propylene-diene monomer (EPDM) composites containing different fiber loadings as well as their behavior after exposure to different doses of electron beam irradiation. Three relaxation processes were evinced, a weak relaxation $\beta$ at sub- $\mathrm{T}_{\mathrm{g}}$ temperatures and two $\alpha$-type relaxations above the $\mathrm{T}_{\mathrm{g}}$. The EPDM/flax composites exhibited higher values of dielectric constant, dielectric loss and conductivity as compared to a pristine EPDM sample. Using thermogravimetric analysis (TG) coupled with Fourier transform infrared spectroscopy (FTIR) and mass spectrometry (MS) (TG/FTIR/MS system), the degradation products can be identified. The water uptake increased as the flax fiber level increased in composites. The water uptake tests of irradiated composites showed that the highest water content was obtained for a flax fiber level of $20 \mathrm{phr}$.
\end{abstract}

Keywords: EPDM rubber; dielectric properties; water uptake; relaxation; thermal stability; IR/TG/MS

\section{Introduction}

Ethylene propylene diene terpolymer (EPDM) is a widely investigated commercially available elastomer. EPDM consists of ethylene and propylene units which provide a chemically saturated and stable backbone and the third monomer is a unconjugated diene. The polymerization reaction can be performed in a controlled way in order to keep the saturated backbone and to place the reactive unsaturation in a side chain where it is available for chemical modifications or vulcanization [1,2]. Due to the presence of the propylene unit, EPDM exhibits high resistance to heat, ozone, weather and high energy radiation. EPDM rubber also possesses flexibility at low temperatures due to the presence of the double bonds, good chemical stability, mainly to polar media, and excellent electrical insulation properties [2-6].

EPDM rubber has several uses in the automotive industry (profiles, hoses, seals), electrical and construction industries, aerospace or nuclear technology. EPDM is also utilized as a dielectric material for cable and wire insulation, especially cables in nuclear power plants which are subjected to thermal and radiation attacks during their utilization, and as an insulator matrix in rocket combustion chambers due to its excellent mechanical, chemical and electrical characteristics [7-10].

EPDM rubber can be vulcanized by peroxides or using a sulfur-accelerated system, which it is the most often used method for this material [3,4]. In comparison with the abovementioned conventional procedures used for vulcanization, radiation crosslinking under accelerated electron beams or $\gamma$-irradiation, affords some advantages because this process takes place at room temperature with different degrees of crosslinking, being a 
clean and fast process, which requires less energy and allows greater processing throughput $[5,11-13]$. Furthermore, the use of radiation crosslinking results in an improvement of the mechanical and electrical characteristics of the EPDM based-materials developed for specific requirements. The incorporation of various additives in the EPDM insulating formulations including reinforcing inorganic fillers, fibrous reinforcement, flame retardants, plasticizers also lead to an improvement of the electrical and mechanical properties of the resulting EPDM composites [2,3,14]. The enhancement in the properties of the reinforced composites can be determined by the higher interfacial interaction between filler and polymer matrix. Adding different levels of reinforcement materials matrix such as carbon fiber, aramid fiber, (nano)silica, PET fibers, carbon black, clay [6,15-20] to the EPDM can assure appropriate electrical properties of the composites and these materials can be profitably for applications in wires and cables subjected to various voltages.

Natural fibers can represent an alternative reinforcement for EPDM composites due to their advantages over carbon and glass fibers such as low production costs, less health risks, biodegradability, etc. [21,22]. From a literature survey, it can be found that few studies on the electrical properties of EPDM/natural fiber composites are reported, as well as the effect of irradiation on their properties. Thus, carrot foliage and corn gluten were used as reinforcing agents for EPDM and the dielectric and mechanical properties of these composites were discussed [23]. An enhancement of the mechanical and dielectric properties of some EPDM/rice husk composites designed as electrical insulators was reported [22]. The dielectric properties of some polypropylene and unsaturated polyester hybrid composites reinforced with bamboo/jute natural fibers were also analyzed taking into account various fiber loadings and ratios. According to the results, the type of polymer used appears to have little influence on the dielectric characteristics of the resulting composites [24].

The present work focused on the dielectric properties of some EPDM/flax composites in terms of dielectric constant, dielectric loss and conductivity. The effect of electron beam irradiation on the dielectric characteristics was analyzed with the respect to different flax loadings. The dielectric relaxation of the EPDM/flax composites was also discussed. The thermal stability of EPDM composites determined using the TG/FTIR/MS techniques and the water absorption properties were reported.

\section{Materials and Methods}

\subsection{Materials}

Ethylene propylene diene monomer (Nordel 4760), with Mooney viscosity of $70 \mathrm{ML}_{1+4}$ at $120^{\circ} \mathrm{C}$, with an ethylene content of $70 \%$ and a density of $0.88 \mathrm{~g} / \mathrm{cm}^{3}$ was supplied by Dow Chemical (Midland, MI, USA). The flax fibers were cut to a length of $3 \mathrm{~mm}$. The features of the working materials presented in Table 1 were detailed in previous publications $[4,14]$. The EPDM/flax fiber composites were obtained by melt mixing on an electrically heated laboratory roll mill machine with a cooling system as described previously $[4,14]$ using the following loadings of flax fibers: 0, 5, 10, 15 and $20 \mathrm{phr}$. The samples were labeled as E0, EF5, EF10, EF15 and EF20, respectively (Table 1).

Table 1. Formulation of EPDM composites.

\begin{tabular}{cccccc}
\hline \multirow{2}{*}{ Material/Code } & \multicolumn{5}{c}{ Loading $\left(\mathbf{p h r}{ }^{*}\right)$} \\
\cline { 2 - 6 } & E0 & EF5 & EF10 & EF15 & EF20 \\
\hline EPDM & 100 & 100 & 100 & 100 & 100 \\
Flax & 0 & 5 & 10 & 15 & 20 \\
PEG 400 & 3 & 3 & 3 & 3 & 3 \\
Irganox 1010 & 1 & 1 & 1 & 1 & 1 \\
Perkadox 14-40B & 8 & 8 & 8 & 8 & 8 \\
\hline${ }^{*}$ parts per hundred rubber. & &
\end{tabular}




\subsection{Methods}

Thermogravimetric analysis of EPDM composites was conducted in dynamic conditions on a STA 449F1 Jupiter instrument (Netzsch, Selb, Germany) in nitrogen atmosphere, at a heating rate of $10^{\circ} / \mathrm{min}$ in the temperature range of $30-700{ }^{\circ} \mathrm{C}$. Samples of $10-15 \mathrm{mg}$ were placed in $\mathrm{Al}_{2} \mathrm{O}_{3}$ crucibles, $\mathrm{Al}_{2} \mathrm{O}_{3}$ being the reference material. The released gases from the TGA instrument were analyzed using an online connected FTIR spectrometer (Vertex 70, Bruker, Ettlingen, Germany) equipped with an external module TGA-IR and an Aeolos QMS 403C mass spectrometer (Netzsch). The IR absorption spectra were obtained over the wavenumber range of $600-4000 \mathrm{~cm}^{-1}$ at a resolution of $4 \mathrm{~cm}^{-1}$. The FTIR transfer line of the evolved gases was made from polytetrafluoroethylene heated at $190{ }^{\circ} \mathrm{C}$. The acquisition of FTIR spectra in 3D format was performed with the OPUS 6.5 software. The gas transfer line to mass spectrometer was made from a quartz capillary heated at $240{ }^{\circ} \mathrm{C}$. QMS 403C spectrometer works at $10^{-5}$ mbar vacuum and electron impact ionization energy of $70 \mathrm{eV}$. The data acquisition was achieved in the range $\mathrm{m} / \mathrm{z}$ of $1-300$, measurement time of $0.5 \mathrm{~s}$.

All sorption measurements were realized with an IGAsorp dynamic sorption analyzer (Hiden Analytical, Warrington, UK) equipped with an ultrasensitive microbalance taking into account the modifications in the sample mass against the temperature and relative humidity. Before sorption experiment, each sample was dried in nitrogen flow $(250 \mathrm{~mL} / \mathrm{min})$ until the weight was in equilibrium at relative humidity $(\mathrm{RH})<1 \%$. The measurements were made at $25^{\circ} \mathrm{C}$ in a $\mathrm{RH}$ range of $0-90 \%$, using humidity steps of $10 \%$, each step having a pre-established equilibrium time between 5 and $10 \mathrm{~min}$.

The measurement of dielectric properties of the EPDM/flax composites was carried out with a broadband dielectric spectrometer (BDS40 system, Novocontrol GmbH, Hundsangen, Germany). The spectrometer was equipped with an Alpha-A high frequency analyzer. The determinations were done over a frequency window of $1-10^{6} \mathrm{~Hz}$ in the temperature range from $-120^{\circ} \mathrm{C}$ to $120^{\circ} \mathrm{C}$. The measured geometry was a plate-capacitor formed by a disc shaped sample having $1 \mathrm{~mm}$ thickness and placed between two round gold-plated flat electrodes of $20 \mathrm{~mm}$ diameter of the test capacitor. All the samples were gold-coated on their both surfaces, in order to assure a good electrical contact between the sample surfaces and the electrodes used to carry the dielectric measurements.

Irradiation of the EPDM/flax composites was achieved on an ALIN10 electron beam accelerator at room temperature as described in [4]. Specimens of rectangular shape $(100 \mathrm{~mm} \times 100 \mathrm{~mm} \times 2 \mathrm{~mm}$ ) were exposed to electron beam irradiation at dosages of 75, 150,300 and $600 \mathrm{kGy}$, respectively.

\section{Results and Discussion}

\subsection{Dielectric Behavior}

In the present study, two main aspects were followed by the dielectric technique: the modification of molecular mobility and the variation of the electrical resistivity for nonirradiated and electron beam irradiated EPDM composites as compared to the initial EPDM sample. The mobility in composites can be firstly affected by the physical immobilization of polymer chains imposed by the flax fibers and then, by the crosslinking process derived from the electron beam irradiation. It is known, that in the EPDM/carbon black composites, NMR relaxation experiments proved unambiguously the immobilization of EPDM chain fragments on the surface of carbon black filler [25]. In this case, physical junctions forming a semi-permanent network in the vicinity of carbon aggregates were evinced. The electrical properties of the composites consisting of two or more phases can also be different depending on the properties of phases. In addition, the presence of fillers in the host polymers creates the conditions for Maxwell-Wagner-Sillars (MWS) polarization due to the difference between the intrinsic electrical properties of the media [26-28]. 


\subsubsection{Evolution of Dielectric Parameters with Frequency and Temperature}

The frequency dependences of the dielectric constant, $\varepsilon^{\prime}$, dielectric loss, $\varepsilon^{\prime \prime}$ and conductivity, $\sigma$, at room temperature for EPDM sample without flax (E0) and EPDM/flax composites are given in Figure 1. It can be seen that $\varepsilon^{\prime}$ decreases as the frequency increases and at higher frequencies it reaches a constant plateau (Figure 1a). At these frequencies the dipoles cannot orient sufficiently rapidly with the oscillations of the electrical field. Also, the orientation polarization decreases because of the restricted mobility of the charges. The numerical values of dielectric constant (Figure 1a inset) were derived from the plateau region, at a frequency of $1 \mathrm{kHz}$. The E0 sample exhibits the lowest magnitude of $\varepsilon^{\prime}$ due to the low polarity of the neat polymer backbone [29]. Besides, the low value of dielectric constant for neat EPDM was observed by other authors [28,29]. The values of dielectric constant for EPDM/flax composites increase gradually with the flax loading. A similar conclusion was reported by Marin-Genesca and coworkers for ethylene propylene diene monomer blended with grinding recycled tire microparticles [28]. We believe that the reactive polar groups of the flax fibers cause an intense dipolar activity and consequently boost the dielectric constant of EPDM/flax composites.
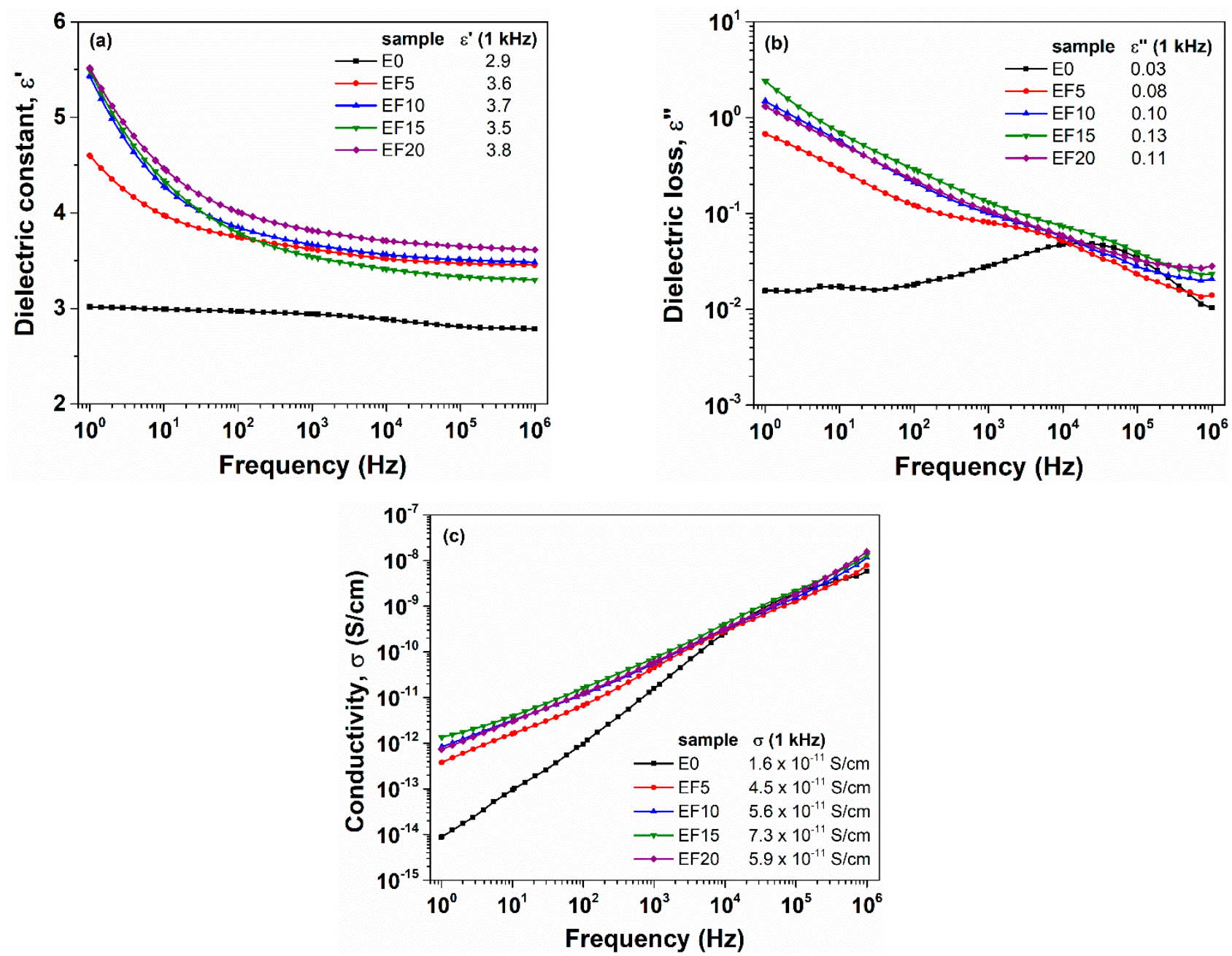

Figure 1. Comparative evolution of the dielectric constant (a), dielectric loss (b) and conductivity (c) as a function of applied field frequency for EPDM composites. The numerical values of dielectric parameters are retrieved in the inset of figures, at a frequency of $1 \mathrm{kHz}$.

As follows from Figure $1 \mathrm{~b}, \mathrm{c}$, the values of $\varepsilon^{\prime \prime}$ and $\sigma$ are relatively low $($ at $\mathrm{f}=1 \mathrm{kHz}$, below 0.1 and $10^{-11} \mathrm{~S} / \mathrm{cm}$, respectively), revealing the insulating character of these composites. In the low frequency range, the dielectric constant and dielectric loss have the highest 
values taking into account the free charges in composites [30]. This effect may be attributed to the interfacial polarization between the EPDM matrix and the flax fibers [31,32]. It is clear that the losses and the conductivity of composites increase slightly with an increasing amount of flax fibers.

Figures 2 and 3 show the frequency dependencies of $\varepsilon^{\prime}(a), \varepsilon^{\prime \prime}(b)$ and $\sigma$ (c) for E0 and EF10 samples, respectively, at different e-beam irradiation doses. Overall, we may notice that the dielectric constant of irradiated samples is enhanced as compared to nonirradiated sample (Figures $2 a$ and $3 a$ ). The effect of e-beam irradiation is remarkable for the pristine EPDM sample (E0), since $\varepsilon^{\prime}$ increases from 2.9 (non-irradiated E0) up to 3.6 (E0-75 irradiated sample), providing, thus, an improvement of about $25 \%$. However, for EF10 composite, only a slight improvement of dielectric constant was observed (about 6-8\%). On the other hand, considering the Figure $2 b, c$, the effect of e-beam irradiation on $\varepsilon^{\prime \prime}$ and $\sigma$ parameters of E0 sample is not clear. However, the dielectric loss and conductivity decrease for irradiated EF10 samples. In our previous work [4], we reported that the electron beam irradiation increased the crosslink density and reduced the crystallization degree of the samples. Following this premise, we may estimate that the improved crosslinking degree of the irradiated samples restricts the transport of charge carriers through the sample's backbone and, consequently, the conductivity of the irradiated samples decreases.
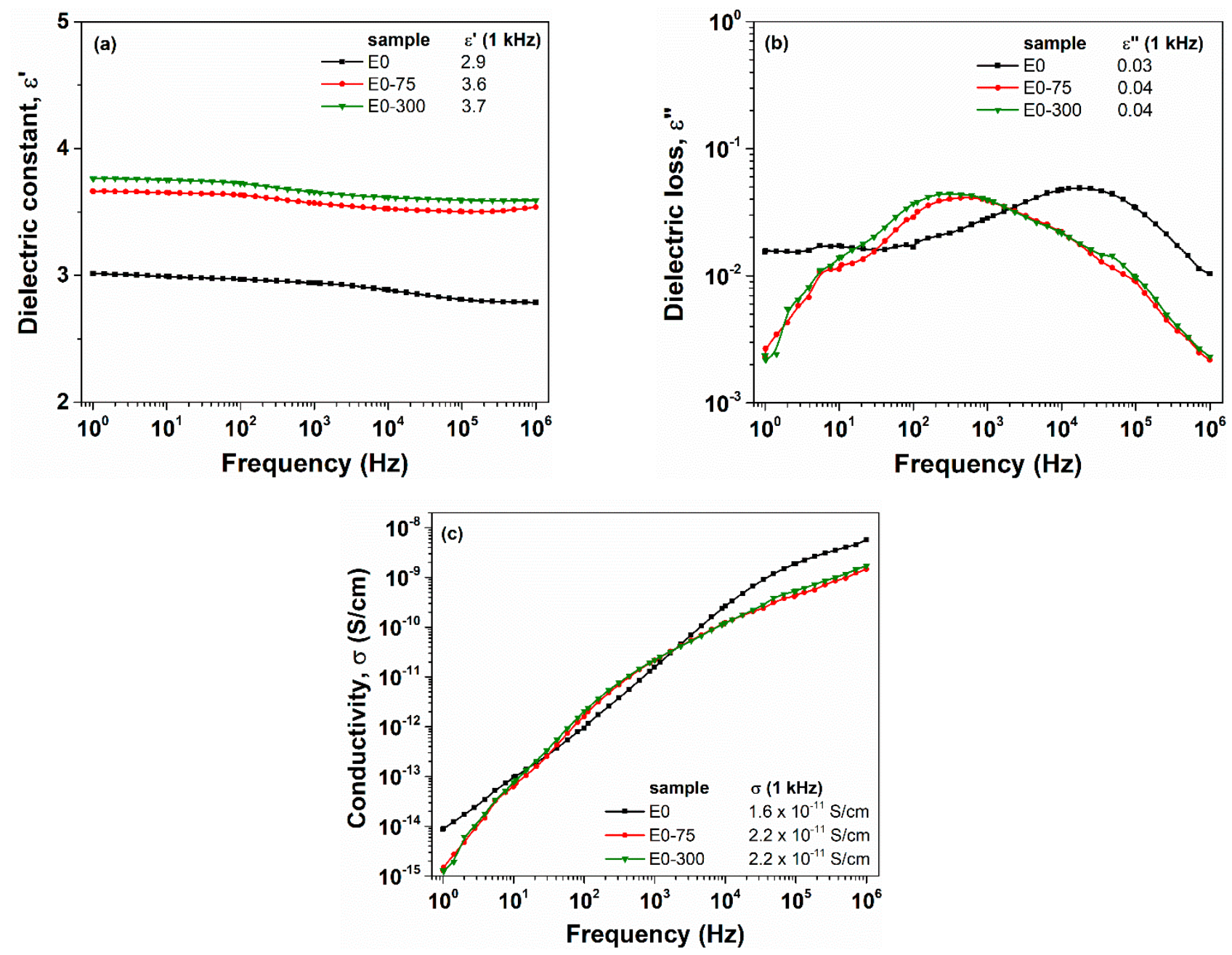

Figure 2. Evolution of the dielectric constant (a), dielectric loss (b) and conductivity (c) as a function of applied field frequency for E0 sample at different irradiation doses. The numerical values of dielectric parameters are retrieved in the inset of figures, at a frequency of $1 \mathrm{kHz}$. 

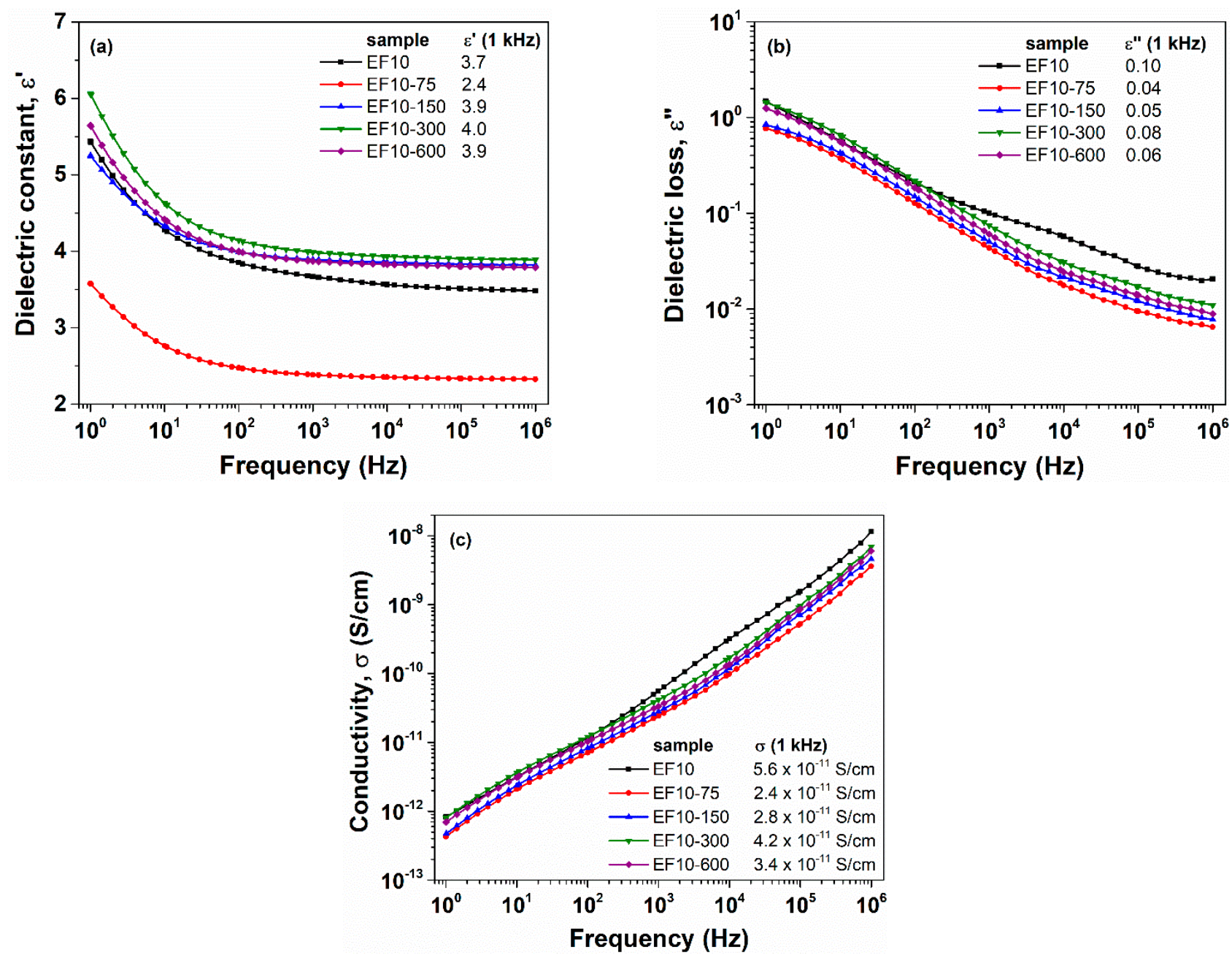

Figure 3. Evolution of the dielectric constant (a), dielectric loss (b) and conductivity (c) as a function of applied field frequency for EF10 sample at different irradiation doses. The numerical values of dielectric parameters are retrieved in the inset of figures, at a frequency of $1 \mathrm{kHz}$.

Figure 4 illustrates a comparison between the values of volume resistivity measured at $1 \mathrm{~Hz}$ for E0 sample and EPDM/flax composites. The incorporation of the flax fibers in the composites determines a decrease of the resistivity even with two orders of magnitude for composites (Figure 4a). The electron beam irradiation applied to pristine EPDM causes the increase of the volume resistivity for irradiated samples (Figure $4 \mathrm{~b}$ ). On the other hand, the irradiated composite EF10 reveals a slight improvement of the insulating properties as a result of irradiation (Figure 4c). High volume resistivity values were also obtained for other EPDM-based composites [30].

In Figure 5, the isothermal plots of $\varepsilon^{\prime}$ and $\varepsilon^{\prime \prime}$ as a function of frequency are presented for EF15 composite at selected temperatures. The other examined samples revealed a similar behavior. According to this figure, the magnitude of the dielectric parameters increases gradually together with the increase of the temperature, revealing some characteristic dipolar relaxation processes. The dielectric relaxations will be further presented.

Figure 6 represents the dielectric behavior of the E0 sample in a temperature domain at fixed frequencies. The dielectric constant and dielectric loss reveal three dipolar relaxations as the temperature increases, noted as $\beta, \alpha$ and $\alpha^{\prime}$, respectively. They are observed like small step increase of $\varepsilon^{\prime}$ and dielectric peaks or shoulders in $\varepsilon^{\prime \prime}$, shifting to higher temperatures with increasing frequency. The secondary $\beta$-relaxation peak can be associated with local motions appearing at lower temperatures than the primary-type $\alpha$-relaxation [13]. Considering the EPDM structure and polarity, two scenarios for the secondary relaxations 
centered at $-110{ }^{\circ} \mathrm{C}$ and up to $-60^{\circ} \mathrm{C}$ with increasing frequency can be taken into account. One possibility is given by the local movement of the diene side units. The second implies that this relaxation occurs by "crankshaft" type motion of the $\mathrm{CH}_{2}$ groups which may have attached some more polar impurities, similar to the low temperature $\gamma$-relaxation observed around $-100{ }^{\circ} \mathrm{C}$ in polyurethanes $[20,33]$.
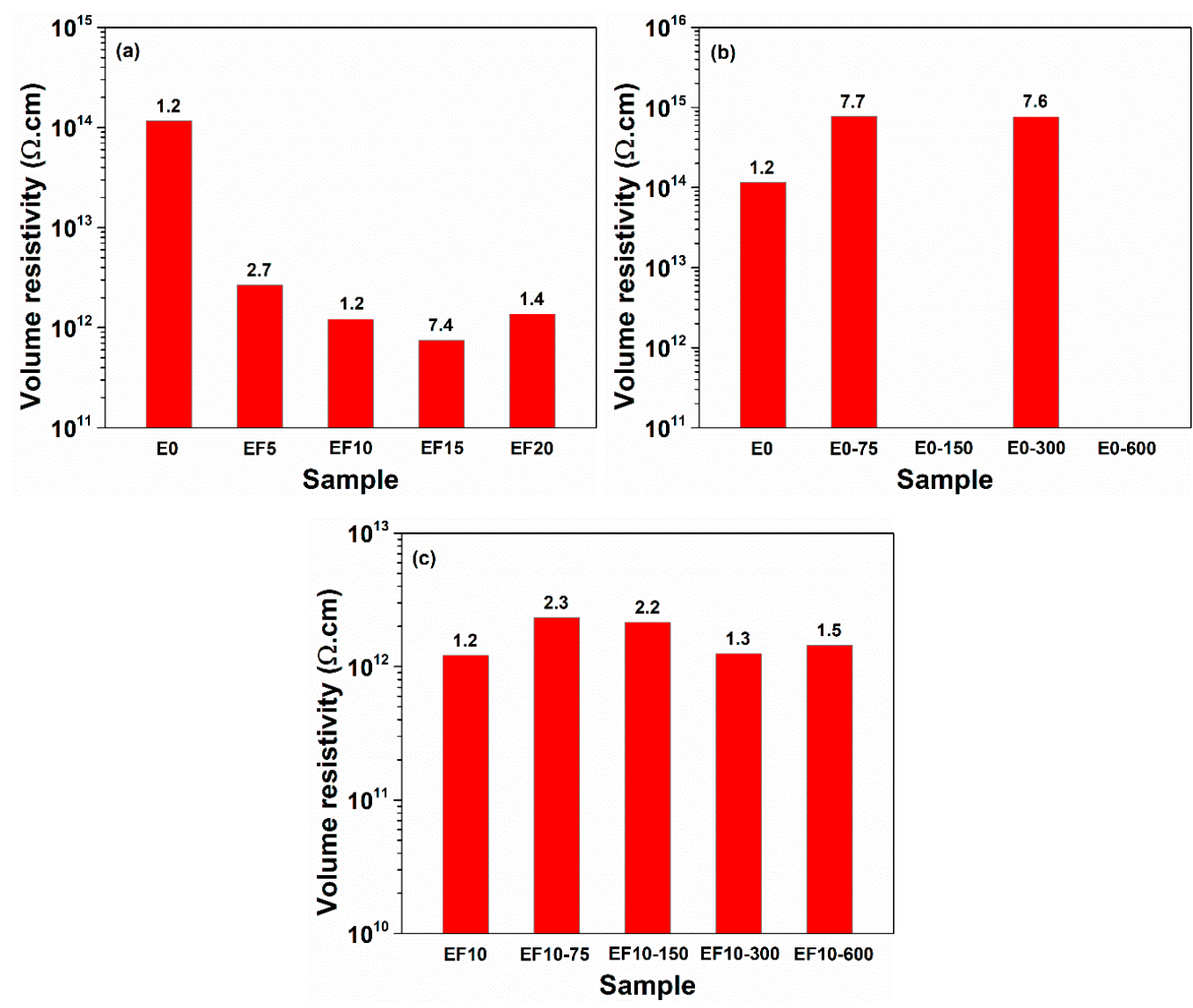

Figure 4. Volume resistivity of EPDM composites versus flax loading (a), and irradiation dose: E0 (b), and EF10 (c). The numerical values of volume resistivity for all considered samples are retrieved at the top of the bar chart, and at a frequency of $1 \mathrm{~Hz}$.
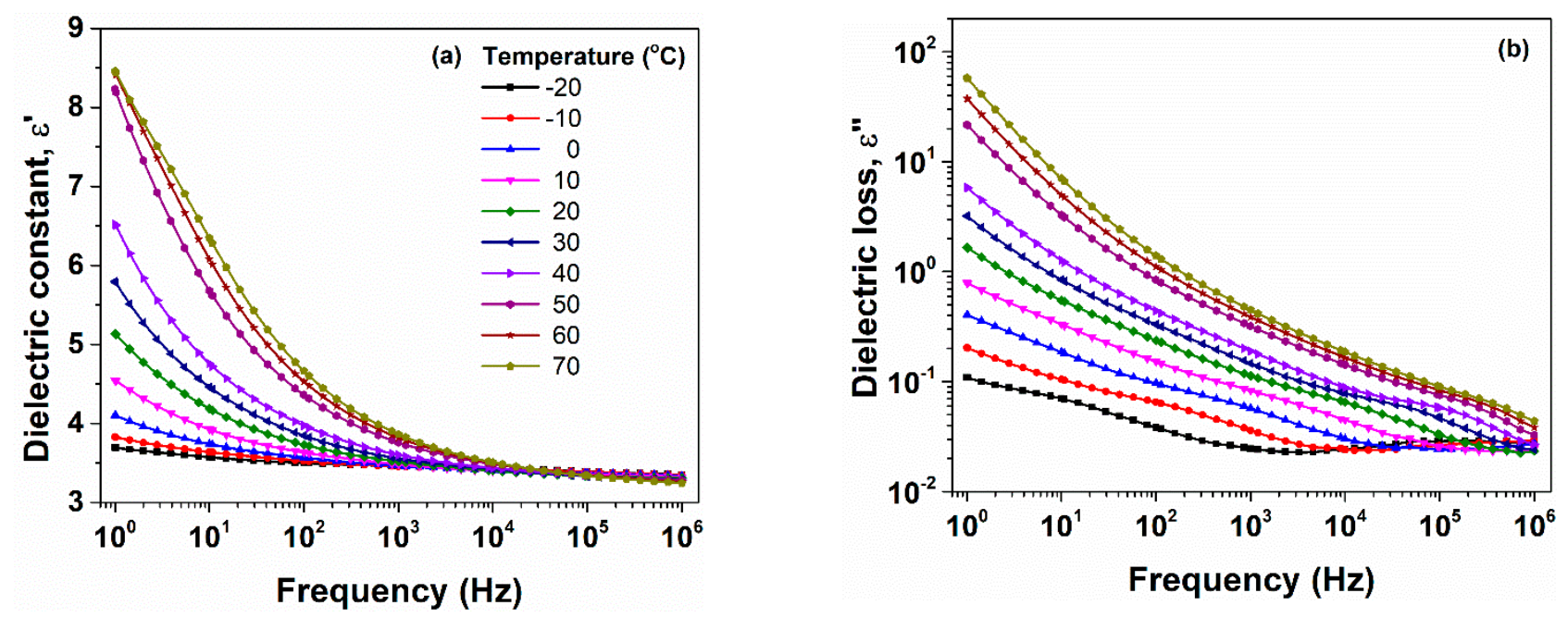

Figure 5. Exemplary evolution of dielectric constant (a) and dielectric loss (b) with frequency at various temperatures, for EF15 sample, as representative example. The legend provided in (a) should be considered for (b) as well. 

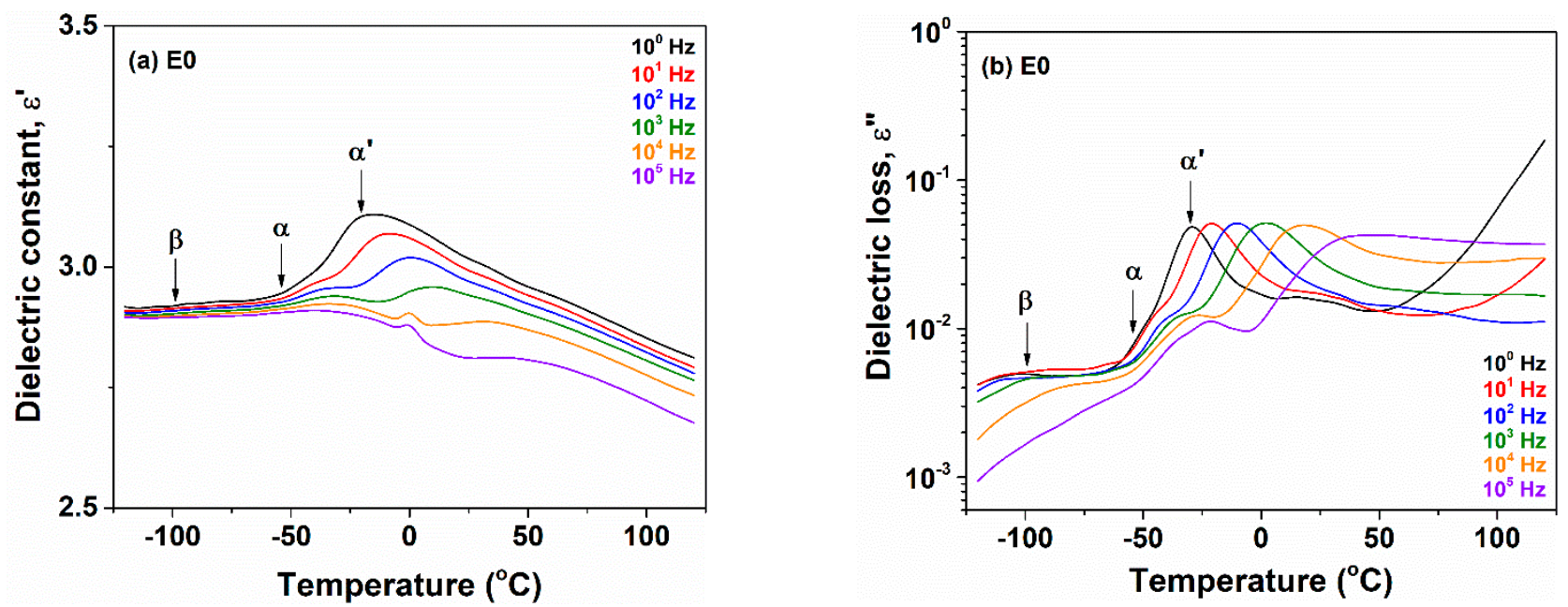

Figure 6. Evolution of dielectric constant (a) and dielectric loss (b) as a function of temperature at different frequencies for E0 sample. The arrows indicate the dielectric peaks of dipolar relaxations.

The variation of dielectric constant and dielectric loss against temperature with respect to frequency is shown in Figure 7 for nonirradiated EF10 composite and in Figure 8 for irradiated at $600 \mathrm{kGy}$ EPDM/flax composite EF10. For the composite EF10, the $\beta$-relaxation remains practically unchanged (Figure 7a,b), whereas for the electron beam irradiated composites this relaxation is widened and slightly shifted to higher temperatures (Figure 8a,b). This means that the relaxation is slower and it has a wider distribution of the relaxation times because the crosslinks restrict the mobility associated with this process.
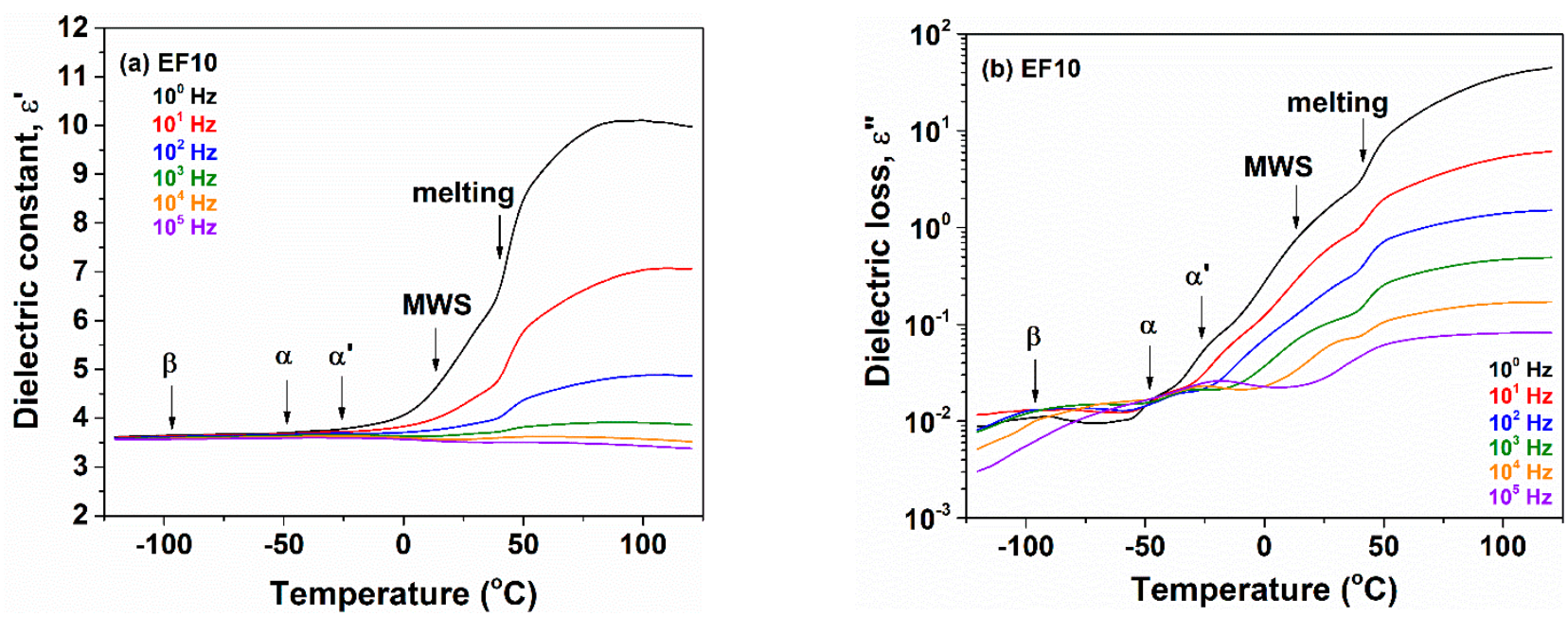

Figure 7. Plots of dielectric constant (a) and dielectric loss (b) as a function of temperature at different frequencies for nonirradiated EF10 composite.

With further increasing temperature, two dielectric relaxations were observed. They are correlated with the glass transition of EPDM chains located in the amorphous phase and among the crystallites, being designed as $\alpha$ and $\alpha^{\prime}$, respectively. For EF10 composite and the irradiated EF10-600 sample, the $\alpha$ and $\alpha^{\prime}$ dipolar relaxations are strongly overlapped in both the $\varepsilon^{\prime}$ and $\varepsilon^{\prime \prime}$ representations. In addition, for composite-type materials, a frequency independent process due to the melting of crystallites is visible with further increases in temperature. This physical process is detected between 40 and $45{ }^{\circ} \mathrm{C}$ for the nonirradiated EF10 composite and $45-50^{\circ} \mathrm{C}$ for the irradiated composite EF10-600. The melting process was previously observed by DSC thermograms between 34 and $46{ }^{\circ} \mathrm{C}$ for EF10 and $40-56{ }^{\circ} \mathrm{C}$ for irradiated samples, respectively, $[4,14]$ confirming the dielectric data. 

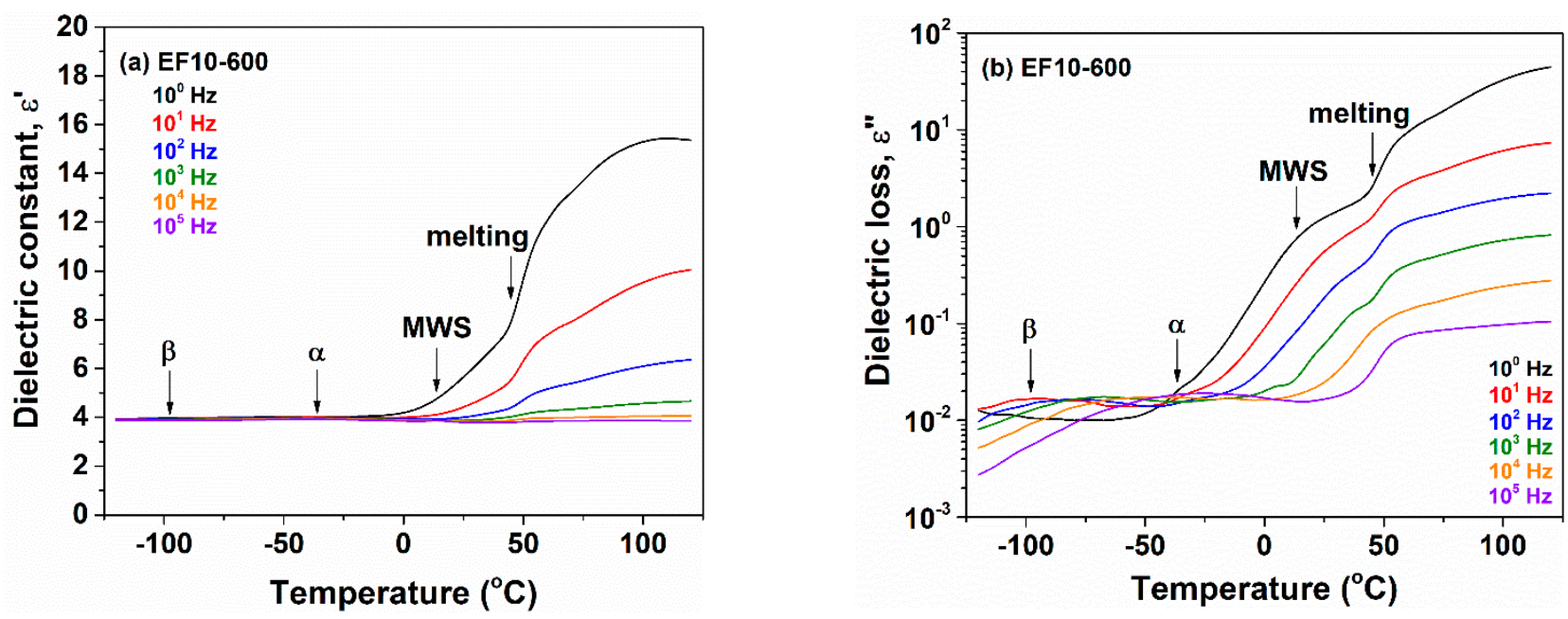

Figure 8. Plots of dielectric constant (a) and dielectric loss (b) as a function of temperature at different frequencies for irradiated EF10-600 composite.

The 3D representations of the dielectric loss as a function of frequency and temperature are rpresented in Figure 9 for simple E0 sample, nonirradiated EF10 and irradiated EF10-600 composites. The diagrams allow the identification of dielectric $\alpha-, \alpha^{\prime}-$ and MWS-relaxations as well as the physical melting transition of crystallites. The broad band of the secondary $\beta$-relaxation is not clearly identified due to high noise presented at low temperatures.

\subsubsection{Segmental Relaxation}

In this section, the detailed analyses of the segmental relaxation will be performed, following the interaction between polymer chains and flax fibers. For this reason, the $\varepsilon^{\prime \prime}(\mathrm{f})$ dependencies were processed based on the Havriliak-Negami $(\mathrm{HN})$ relation:

$$
\varepsilon^{*}=\varepsilon^{\prime}-\mathrm{i} \varepsilon^{\prime \prime}=\varepsilon_{\infty}+\frac{\Delta \varepsilon}{\left[1+\left(\mathrm{i} \omega \tau_{\mathrm{HN}}\right)^{\alpha_{\mathrm{HN}}}\right]^{\beta_{\mathrm{HN}}}}
$$

where $\Delta \varepsilon$ is the relaxation strength of the dipolar process, $\omega=2 \pi \mathrm{f}$ represents the angular frequency, $\mathrm{f}$ is the alternating field frequency, $\tau_{\mathrm{HN}}$ is the $\mathrm{HN}$ relaxation time of the dipolar process, $\alpha_{\mathrm{HN}}$ and $\beta_{\mathrm{HN}}$ are the shape-related parameters of the dielectric peak [34]. Furthermore, the specific relaxation time attributed to the peak maxima, $\tau_{\max }$, was evaluated with the following expression:

$$
\tau_{\max }=\tau_{\mathrm{HN}}\left[\frac{\sin \frac{\pi \mathrm{ab}}{2+2 \mathrm{~b}}}{\sin \frac{\pi \mathrm{a}}{2+2 \mathrm{~b}}}\right]^{\frac{1}{a}}
$$

The main relaxation peaks, $\alpha$ and $\alpha^{\prime}$, are related to the cooperative reorientation motions of the main segments. As previously noticed, the $\alpha$-relaxation exhibits as a dielectric peak with reduced intensity. It is strongly overlapped by the $\alpha^{\prime}$-relaxation and, consequently, its curvature cannot be exactly identified and processed. On the other hand, $\alpha^{\prime}$-relaxation appears as a well-shaped dielectric peak with high intensity. This signal will be further processed for simple E0 polymer, EF5, EF10 and EF15 nonirradiated composites and also for E0-75 and E0-300 irradiated composite samples. For other samples, we believe that the dielectric peak specific to $\alpha^{\prime}$-relaxation is suppressed by the crosslinking process. The activation energy of the segmental $\alpha^{\prime}$-relaxation, $\mathrm{B}$, was finally determined with the Vogel-Fulcher-Tammann (VFT) expression:

$$
\tau_{\max }(T)=\tau_{0} \exp \left(\frac{B}{k\left(T-T_{V}\right.}\right)
$$


where, $\tau_{0}$ is a prefactor, $\mathrm{k}$ is the Boltzmann's constant, $\mathrm{T}$ is the absolute temperature and $\mathrm{T}_{\mathrm{v}}$ is the so-called Vogel temperature.
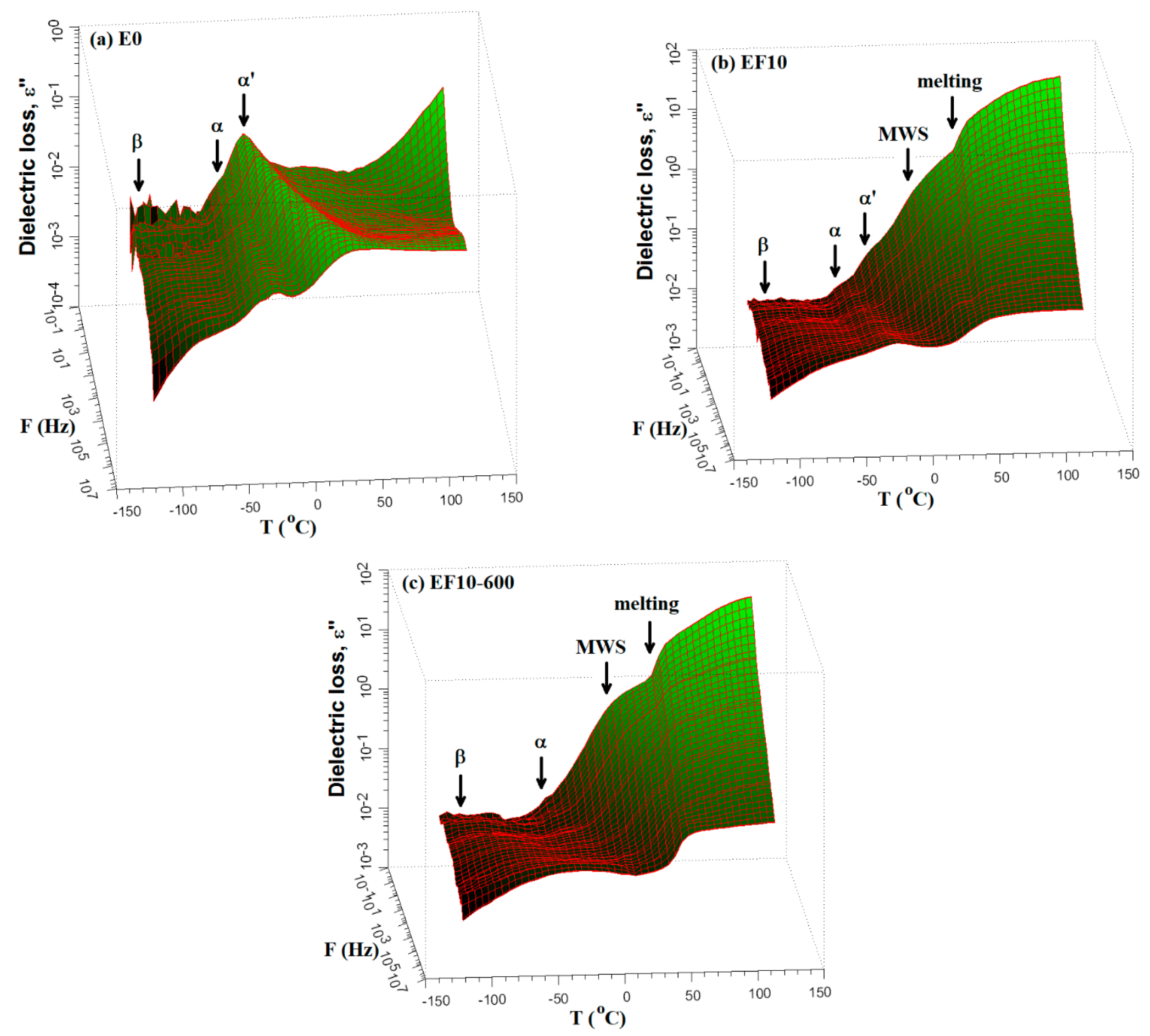

Figure 9. Variation of the dielectric loss with frequency and temperature for E0 (a), nonirradiated EF10 (b) and irradiated EF10-600 composites (c).

Figure 10a shows the isothermal plots of dielectric loss as a function of frequency for an E0 sample at selected temperatures between $-30{ }^{\circ} \mathrm{C}$ and $30^{\circ} \mathrm{C}$. The well-shaped relaxation peak is shifted to higher frequencies as temperature increases, suggesting that the $\alpha^{\prime}$ dipolar transition is a thermally activated process. Following the Figure 10a, it is revealed that each $\varepsilon^{\prime \prime}(\mathrm{f})$ dependency was fitted with two HN terms: the first one retrieved at low frequencies (maximum around $15 \mathrm{~Hz}$ ) describes the dielectric peak of $\alpha^{\prime}$ relaxation and the second one observed at higher frequencies (maximum around $10^{5} \mathrm{~Hz}$ ) related to the peak of $\alpha$-relaxation. A supplementary term for the MWS process is limited at low frequencies. The dielectric peak of $\alpha^{\prime}$ relaxation was found asymmetric $\left(\beta_{\mathrm{HN}} \sim 0.7-0.8\right)$ and narrow $\left(\alpha_{\mathrm{HN}} \sim 0.55-0.65\right)$. Closed values of $\beta_{\mathrm{HN}}$ and $\alpha_{\mathrm{HN}}$ were also found for EF5, EF10 and EF15 nonirradiated composites. 

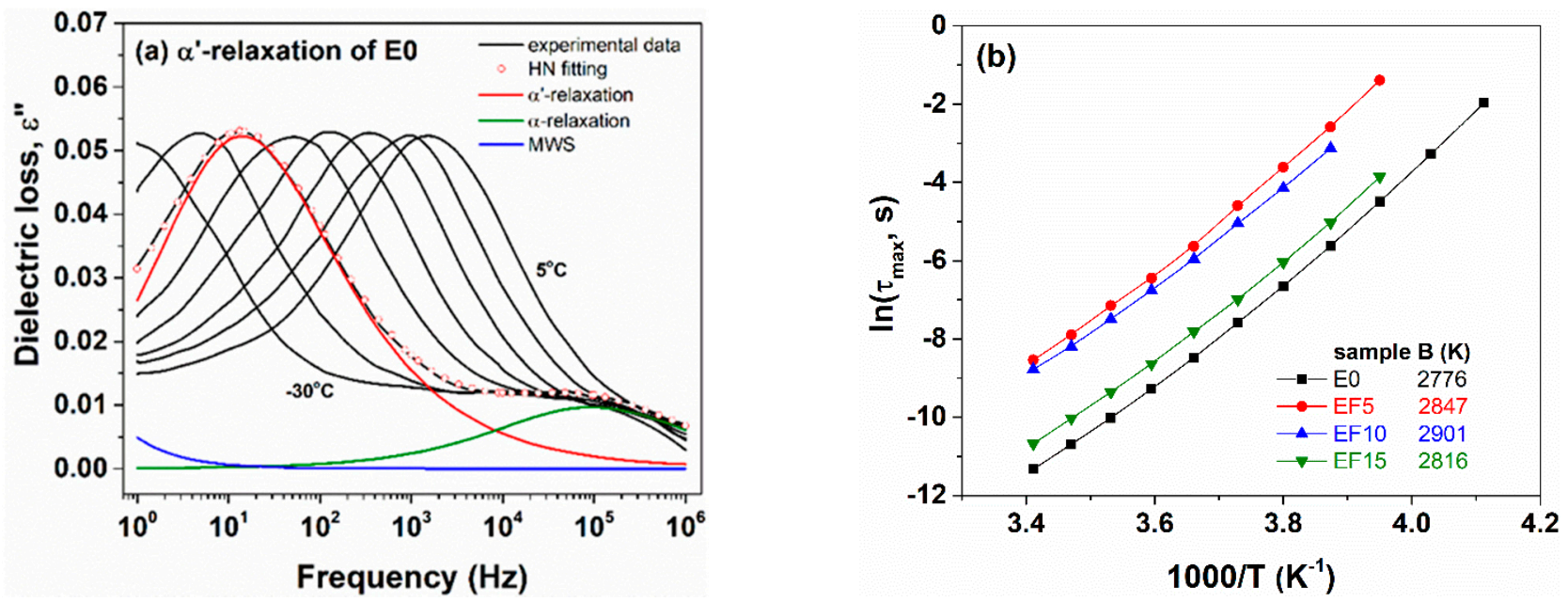

Figure 10. Representative separation of $\alpha^{\prime}$-relaxation for E0 sample (a) and Arrhenius plots for nonirradiated composites (b). In (b), lines are used to guide the eyes.

The activation energy of E0 polymers and the corresponding composites are quite close (Figure 10b inset), suggesting that the content of flax fibers does not affect excessively the segmental molecular dynamics of the polymer. However, B values of nonirradiated composites are slightly lower than that of E0 polymer meaning that the flax fibers may reduce the rotational potential energy barrier for segmental motions of the polymer backbone. The results are in agreement with the thermal investigations of composites based on ethylene propylene diene rubber reinforced with flax fibers. In a previous work [14] we noticed that the $\mathrm{T}_{\mathrm{g}}$ values of $\mathrm{E} 0$ and composites are comparable.

The $\varepsilon^{\prime \prime}(\mathrm{f})$ dependencies of E0-300 sample at temperatures between 10 and $40{ }^{\circ} \mathrm{C}$ are displayed in Figure 11a. We notice that $\alpha^{\prime}$-relaxation of irradiated composites is also a thermally activated process, following the VFT equation (3). The deconvolution procedure is depicted in Figure 11a for the $\varepsilon^{\prime \prime}(\mathrm{f})$ dependency presented at $20{ }^{\circ} \mathrm{C}$. Here, the HN functions of $\alpha^{\prime}$ (depicted at $80 \mathrm{~Hz}$ ), $\alpha$ (depicted around $3 \times 10^{4} \mathrm{~Hz}$ ) and a small term for the dielectric signal of MWS are enclosed. The HN shape parameters for $\alpha^{\prime}$-relaxation of E0-300 sample were obtained as $\beta_{\mathrm{HN}} \sim 0.75$ and $\alpha_{\mathrm{HN}} \sim 0.65$ (on average over temperature), being similar with that of nonirradiated composites. However, according to Figure 11b, the values of activation energy of irradiated samples are higher than B value of sample E0 and, thus, of nonirradiated composites. It is clear that the crosslinking of composites due to e-beam irradiation restricted the segmental motions of the polymer backbone. The effect is in agreement with the previous findings by DSC, where the values of $\mathrm{T}_{\mathrm{g}}$ for e-beam irradiated composites increased with the irradiation dose due to the reduced molecular mobility provided by crosslinking [4].

\subsection{Thermal Behavior}

Figure 12 presents the TG and the corresponding derivative (DTG) curves of E0 and of $300 \mathrm{kGy}$ irradiated composites E0 and EF20 in nitrogen atmosphere at a heating rate of $10^{\circ} \mathrm{C} / \mathrm{min}$. The TGA of the EPDM/flax fiber formulations showed practically a similar behavior, the incorporation of the flax fibers in the EPDM matrix did not change significantly the thermal degradation parameters of the composites due to the uniform dispersion of the flax fibers in polymer composite which permits adding a higher fiber level. The thermal stability of the irradiated composites was slightly higher as compared to non-irradiated sample due to the crosslinking of the polymer chains. It can be seen that the EPDM samples exhibited one main step of thermal degradation that can be due to the decomposition of the rubber organic materials $[4,14]$. The maximum decomposition temperatures of EPDM samples were as follows: 468,471 and $471{ }^{\circ} \mathrm{C}$ for E0, E0 and EF20 irradiated at $300 \mathrm{kGy}$, respectively. Also, the temperature at which the maximum amounts 
of gases were evolved (from Gram-Schmidt curve) corresponds to $475{ }^{\circ} \mathrm{C}$ (E0), $472{ }^{\circ} \mathrm{C}$ (E0, $300 \mathrm{kGy})$ and $480{ }^{\circ} \mathrm{C}(\mathrm{EF} 20,300 \mathrm{kGy})$.
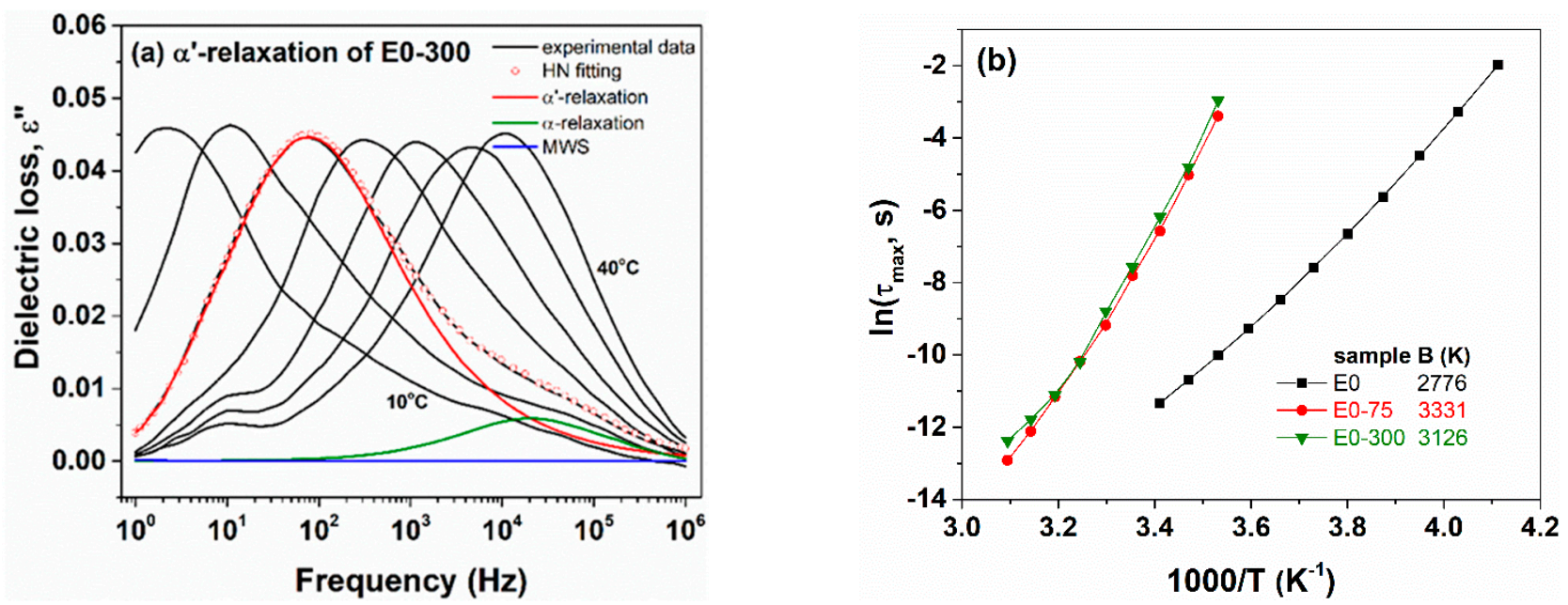

Figure 11. Representative separation of $\alpha^{\prime}$-relaxation for E0-300 sample (a) and Arrhenius plots for irradiated E0, E0-75 and E0-300 composites (b). In (b), lines are used to guide the eyes.
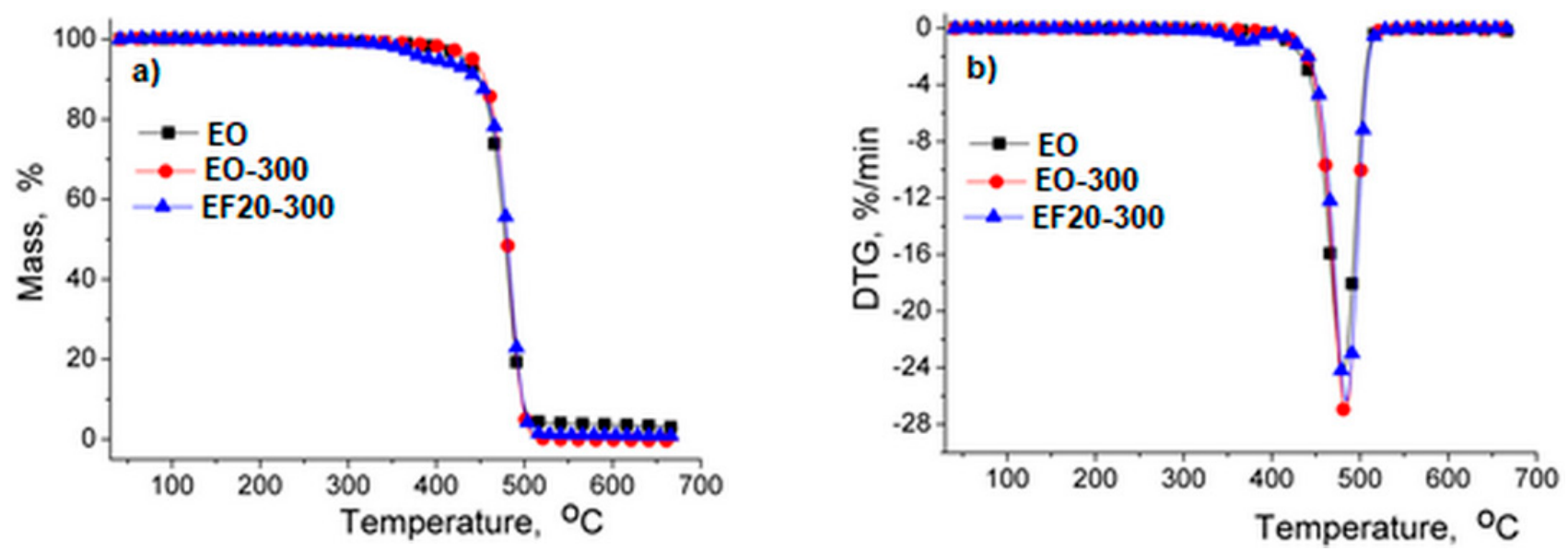

Figure 12. (a) TG and (b) DTG curves for EPDM samples under nitrogen atmosphere.

In order to study the thermal stability and the degradation mechanism of the EPDM and corresponding composites, TG-FTIR analysis was applied. The low molecular weight volatile compounds arising during thermal degradation were identified by TG/FTIR/MS simultaneous analysis. The 3D FTIR diagrams resulting from the thermal decomposition of the EPDM samples are presented in Figure 13. The presence of evolved gases was observed after $400{ }^{\circ} \mathrm{C}$ when the decomposition process occurs according to TG/DTG data. From the FTIR staked plot diagrams, the bidimensional FTIR spectra were extracted corresponding to the temperatures at which the degradation rate is maximum: $475{ }^{\circ} \mathrm{C}$ for E0 and $480{ }^{\circ} \mathrm{C}$ for EF20 (Figure 14). The main absorption bands are located in the proximity of the following values: 3749-2400, 3078-3010, 2925-2853, 2300-2400, 1778, 1705, 1646, $1520,1455,1300-1200,1118-1064,883-612 \mathrm{~cm}^{-1}$, respectively. The absorption band around $3200 \mathrm{~cm}^{-1}$ (ice band) is characteristic of the MCT detector (cooled with liquid nitrogen) of the TG-IR external module. The absorption bands located at 3749-3566 and 1295-1375 $\mathrm{cm}^{-1}$ $(v \mathrm{OH})$ can be assigned to water vapors and the bands around $2360-2300$ and $668 \mathrm{~cm}^{-1}$ to carbon dioxide. The specific signals of the $\mathrm{CH}, \mathrm{CH}_{2}$ and $\mathrm{CH}_{3}$ groups $(v \mathrm{CH}$ stretching vibrations) of aliphatic saturated derivatives correspond to the absorption bands around 2925-2853, 1375-1294, 712-720 $\mathrm{cm}^{-1}$ and aliphatic unsaturated derivatives $(v C=C)$ show 
absorption bands in the range of $1646-1688 \mathrm{~cm}^{-1}[35,36]$. Furans and furan derivatives (furan aldehyde, furanone) present stretching vibrations, $v C=C$, at $1570-1517 \mathrm{~cm}^{-1}, v \mathrm{CH}$ at $899 \mathrm{~cm}^{-1}$ and $v C=\mathrm{O}$ groups specifically of furan ring at $1124-1067 \mathrm{~cm}^{-1}$. The aromatic derivatives show absorption bands at $3078-3010 \mathrm{~cm}^{-1}(\nu \mathrm{CH})$, ring vibrations, $v \mathrm{C}=\mathrm{C}$, at $1456 \mathrm{~cm}^{-1}$ and substitution bands, $\gamma \mathrm{CH}$, at $952,821 \mathrm{~cm}^{-1}$.
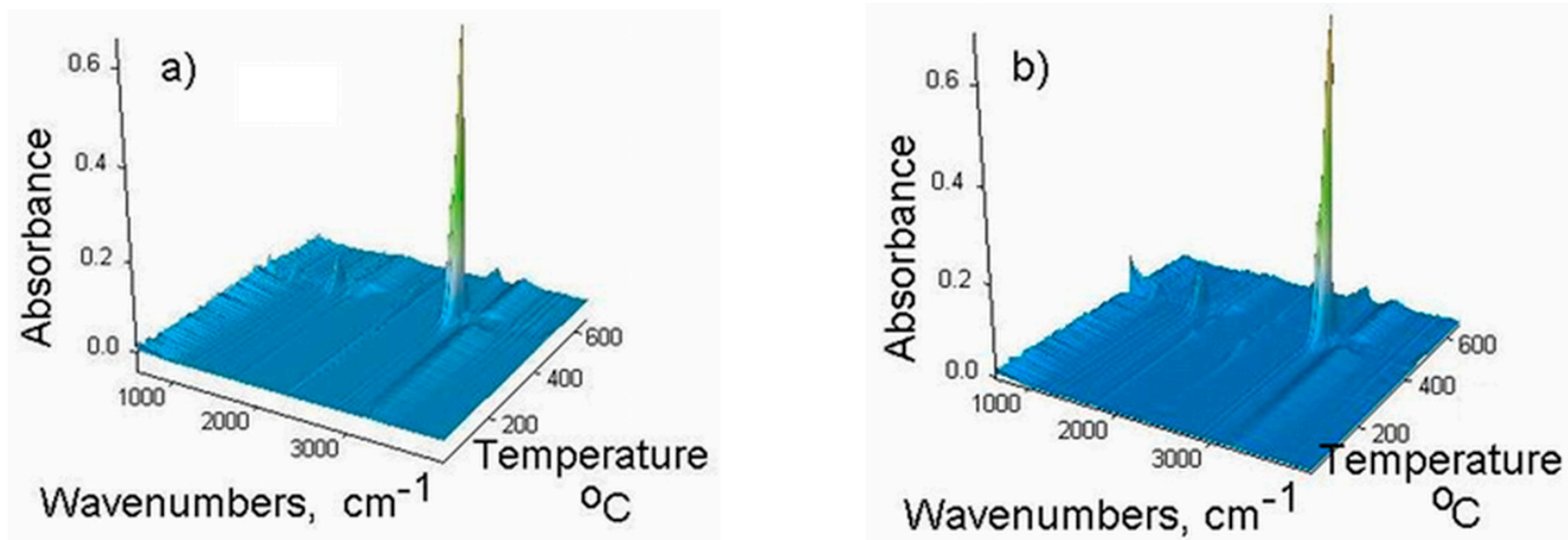

Figure 13. 3D FTIR spectra of the evolved gases during thermal degradation for (a) E0; (b) EF20.
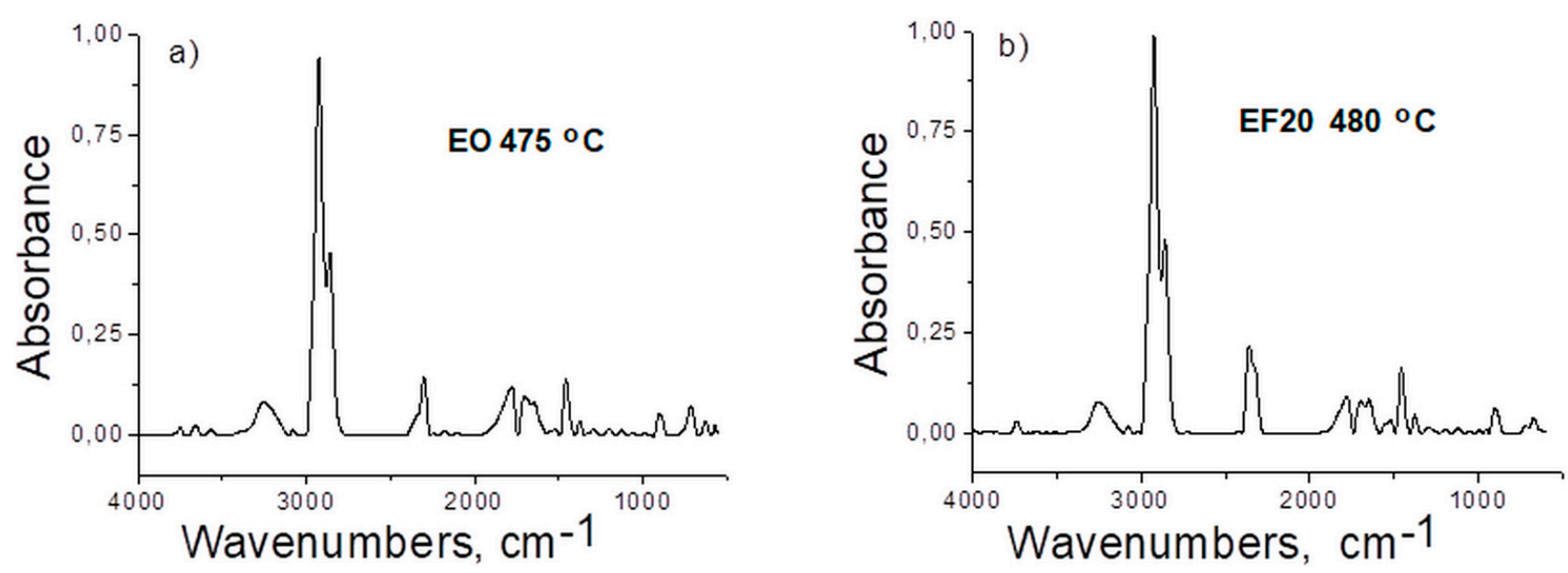

Figure 14. FTIR spectra of the evolved products for (a) E0 at $475^{\circ} \mathrm{C}$ and (b) EF20 at $480{ }^{\circ} \mathrm{C}$.

MS signals represented by $\mathrm{m} / \mathrm{z}$ values at the temperature $\left(\mathrm{T}_{\max }\right)$ corresponding to the maximum amount of released gases are given in Figures 15 and 16. The chemical composition of the evolved gases during thermal degradation was determined on the basis of FTIR and mass spectra (MS) available in the NIST spectral libraries [37]. The main pyrolysis products detected by MS spectra, at a heating rate of $10^{\circ} \mathrm{C} / \mathrm{min}$, confirmed the data obtained by the FTIR technique. The $m / z$ signals given in Figure 15 can be associated with destruction of the EPDM polymer chains. The main ionic fragments obtained at high temperatures $\left(475^{\circ} \mathrm{C}\right)$ correspond to water $\left(\mathrm{H}_{2} \mathrm{O}^{+}\right) \mathrm{m} / z=18,17,16$; carbon dioxide $\left(\mathrm{CO}_{2}{ }^{+}\right)$ $m / z=44,28,16,12,45 ;$ alkane and alkene derivatives such as propylene $\left(\mathrm{C}_{3} \mathrm{H}_{6}{ }^{+}\right) \mathrm{m} / z=42$, $41,39,27,40,38,37,26,15)$; propane $\left(\mathrm{C}_{3} \mathrm{H}_{8}{ }^{+}\right) \mathrm{m} / z=44,29,27,43,39,41,26,15,42$; butane $\left(\mathrm{C}_{4} \mathrm{H}_{10}{ }^{+}\right) \mathrm{m} / z=58,43,29,27,28,41,39,42,15,26$; hexene $\left(\mathrm{C}_{6} \mathrm{H}_{12}{ }^{+}\right) \mathrm{m} / z=84,56,41,42,55$, $43,27,39,69,29$; heptene $\left(\mathrm{C}_{7} \mathrm{H}_{14}{ }^{+}\right) \mathrm{m} / z=98,56,41,55,29,42,70,69,57,39,27$; norbornene $\left(\mathrm{C}_{7} \mathrm{H}_{10}{ }^{+}\right) \mathrm{m} / \mathrm{z}=94,66,39,79,67,77,65,27,40,41 ;$ 5-ethylidene 2-norbornene $\left(\mathrm{C}_{9} \mathrm{H}_{12}{ }^{+}\right)$ $m / z=120,66,91,105,78,39,77,79,65,92$; trimethylcyclohexane $\left(\mathrm{C}_{9} \mathrm{H}_{18}{ }^{+}\right) m / z=126,69$, $111,55,41,39,56,70,42,112$; aromatic derivatives such as, benzene $\left(\mathrm{C}_{6} \mathrm{H}_{6}{ }^{+}\right) \mathrm{m} / z 78,77,51$, $50,52,39,70,76,38$ and toluene $\left(\mathrm{C}_{7} \mathrm{H}_{8}{ }^{+}\right) \mathrm{m} / \mathrm{z}=92,91,65,39,63,51,93,50,89,62$. 


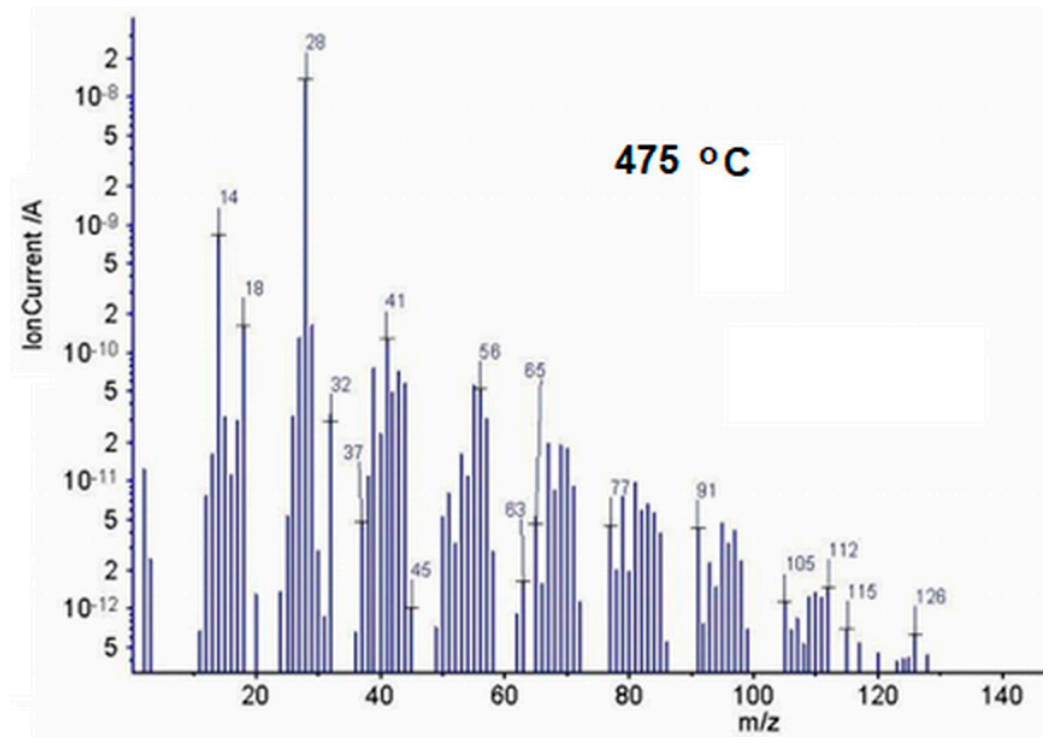

Figure 15. Mass spectrum of the evolved gases by thermal degradation of E0 sample, at $475{ }^{\circ} \mathrm{C}$.
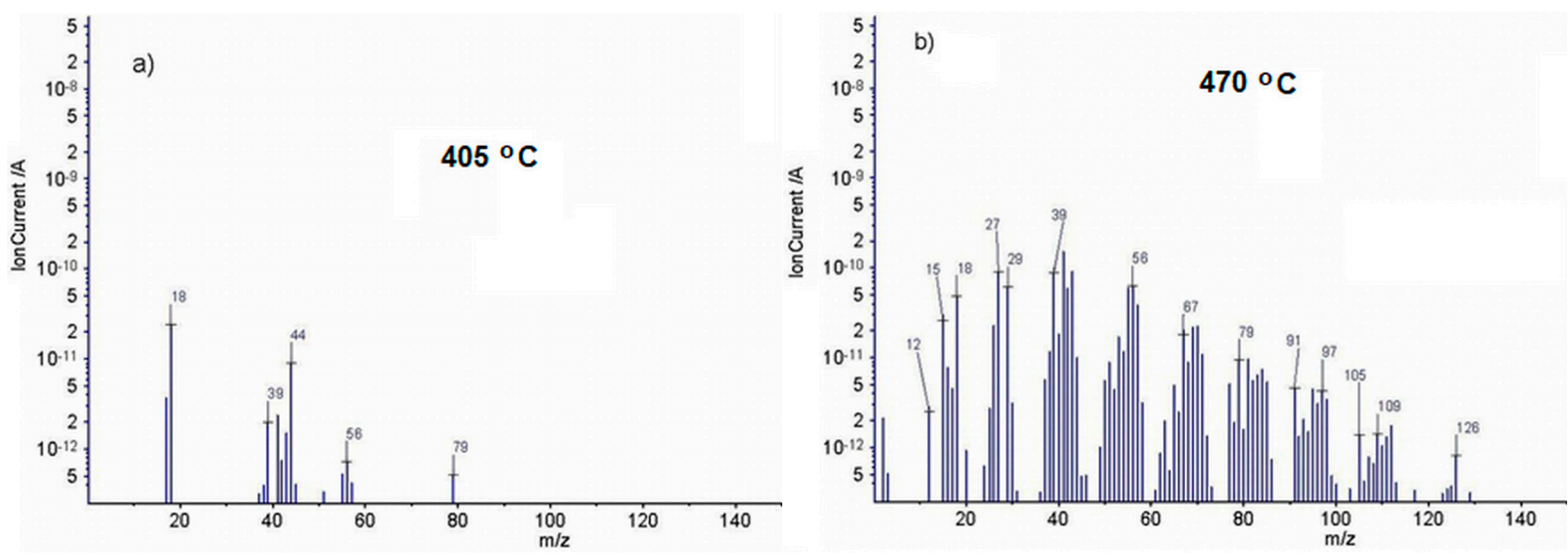

Figure 16. Mass spectra of the evolved gases by thermal degradation of EF20 sample at (a) $405^{\circ} \mathrm{C},(\mathbf{b}) 470{ }^{\circ} \mathrm{C}$.

In the MS spectra of EPDM/flax composite (EF20) an additional process of thermal degradation occurring up to $400{ }^{\circ} \mathrm{C}$ was found. In this range water, carbon dioxide as well as ionic fragments of some aliphatic $\left(\mathrm{C}_{4} \mathrm{H}_{8}{ }^{+}\right)$or aromatic $\left(\mathrm{C}_{6} \mathrm{H}_{7}{ }^{+}\right)$derivatives can appear (Figure 16a). Besides, the majority of MS signals evidenced for sample E0 was also identified for sample EF20 excepting the signals with $m / z=120$ (Figure 16b). On the other hand, during thermal decomposition of EPDM/flax composite at $475{ }^{\circ} \mathrm{C}$ different ionic fragments provided by flax fibers containing waxes, greases, lignin, hemicellulose and pectic compounds can appear. These products can generate by pyrolysis processes different ionic fragments, such as furan $\left(\mathrm{C}_{4} \mathrm{H}_{4} \mathrm{O}^{+}\right) \mathrm{m} / \mathrm{z}=68,39,38,40,29,37,42$, 60; furan aldehyde $\left(\mathrm{C}_{5} \mathrm{H}_{4} \mathrm{O}_{2}{ }^{+}\right) \mathrm{m} / z=96,95,39,38,29,37,67,40,97,42 ; 2(5 \mathrm{H})$-furanone $\left(\mathrm{C}_{4} 4{ }_{4} \mathrm{O}_{2}{ }^{+}\right)$ $m / z=84,55,27,26,54,29,39,38,27 ; 5$-methyl-2-furaldehyde $\left(\mathrm{C}_{6} \mathrm{H}_{6} \mathrm{O}_{2}{ }^{+}\right) \mathrm{m} / z=110,109$, $53,27,39,51,81,43,51,111$ [35].

\subsection{Water Sorption}

The sorption/desorption isotherms are illustrated in Figure 17. According to the IUPAC classification, these isotherms can be considered as type IV with $\mathrm{H} 2$ hysteresis loops characteristic of pores with an irregular array of shapes and sizes, illustrating the adsorption behavior of mesoporous materials [38,39]. 

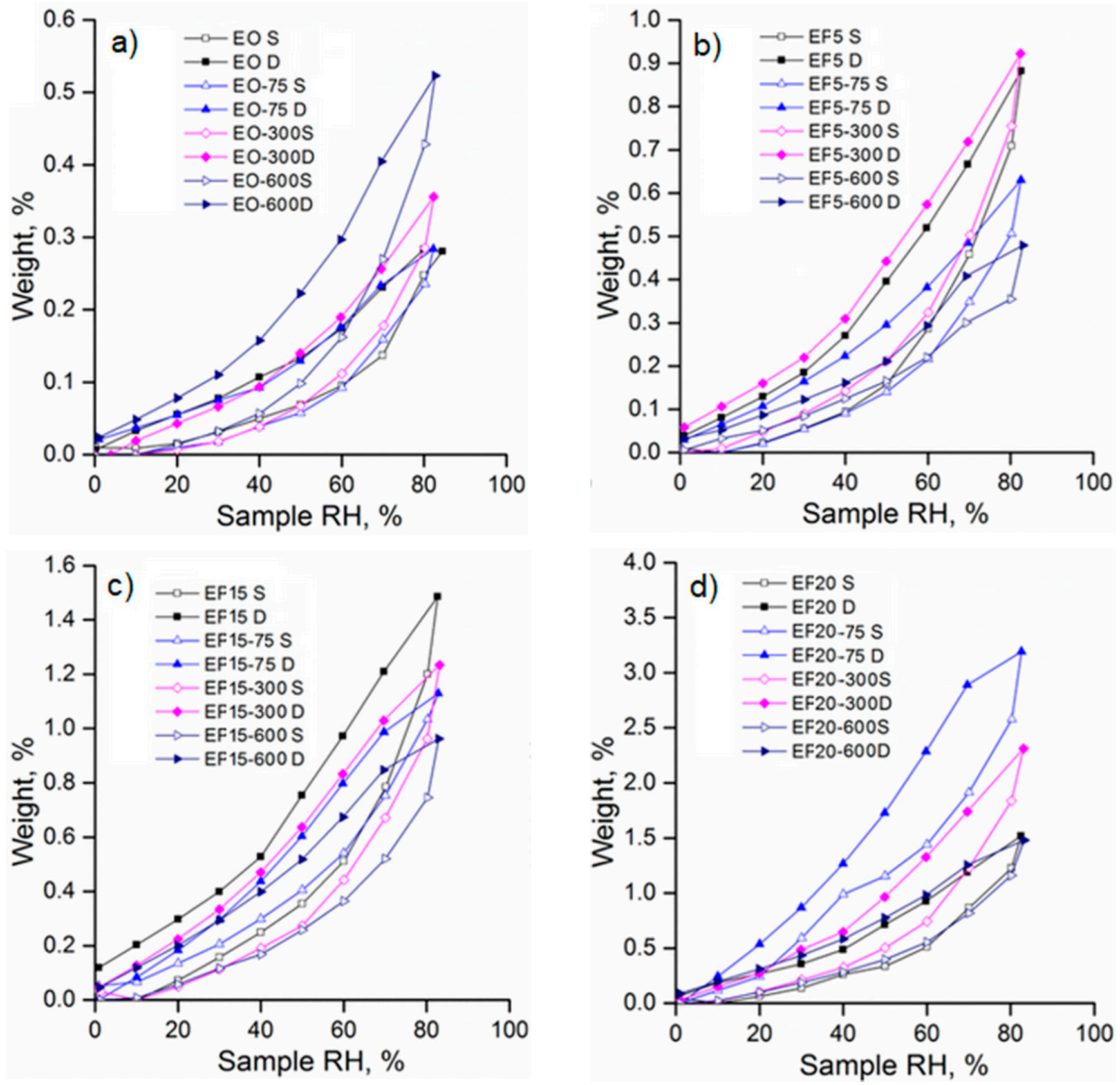

Figure 17. Sorption/desorption isotherms of EPDM composites (a) E0; (b) EF5; (c) EF15; (d) EF20 (S-sorption, D-desorption).

Different methods have been developed to estimate the diffusion coefficients by solving the second Fick's equations [40,41]:

$$
\begin{gathered}
\frac{M_{t}}{M_{\infty}}=\frac{4}{h}\left(\frac{D t}{\pi}\right)^{0.5}+\frac{8}{h}(D t)^{0.5} \sum_{n=1}^{\infty}(-1)^{n} \operatorname{ierfc} \frac{n h}{2(D t)^{0.5}} \\
\frac{M_{t}}{M_{\infty}}=1-\frac{8}{\pi^{2}} \sum_{n=0}^{\infty} \frac{1}{(2 n+1)^{2}} e^{\frac{-(2 n+1)^{2} \pi^{2} D t}{h}}
\end{gathered}
$$

where $t$ is the time measured when the concentration was changed, $h$ represents thickness of the materials, $M_{o}$ is the initial equilibrium mass, $M_{t}=M_{o}-M_{t o} \ldots t \infty$ denotes the change in mass from $M_{o}$ to the new equilibrium mass $M_{t}$, ierfc represents the integral of the error function complement. 
Taking into account the approximation of the first terms in Equations (4) and (5), at sufficiently short times, $M_{t} / M_{\infty}<0.5$ and sufficiently long times, $M_{t} / M_{\infty}>0.5$, one can write that:

$$
\left(\frac{M_{t}}{M_{\infty}}\right)^{2}=\frac{16 D_{1}}{\pi h^{2}} t=K_{1} t
$$

where:

$$
\begin{gathered}
K_{1}=-\frac{16 D_{1}}{\pi h^{2}} \Rightarrow D_{1}=-\frac{K_{1} \pi h^{2}}{16} \\
\ln \left(1-\frac{M_{t}}{M_{\infty}}\right)=\ln \frac{8}{\pi^{2}}-\frac{D_{2} \pi^{2}}{h^{2}} t=K_{2} t
\end{gathered}
$$

where:

$$
K_{2}=-\frac{D_{2} \pi^{2}}{h^{2}} \Rightarrow D_{2}=-\frac{K_{2} h^{2}}{\pi^{2}}
$$

Using the above diffusion models the results regarding the water uptake for EPDM/flax fiber composites are presented in Table 2. The Brunauer-Emmet-Teller (BET) model was chosen to fit the water sorption isotherms [42]:

$$
W=\frac{W_{m} \cdot C \cdot p / p_{0}}{\left(1-p / p_{0}\right) \cdot\left(1-p / p_{0}+C \cdot p / p_{0}\right)}
$$

where $W$ is the weight of adsorbed water, $W_{m}$ is the weight of water forming a monolayer,

\begin{tabular}{|c|c|c|c|c|c|c|}
\hline \multirow[b]{2}{*}{ Sample } & \multirow{2}{*}{$\begin{array}{c}\text { Sorption } \\
\text { Capacity, } \\
\% \text { d.b. }\end{array}$} & \multirow[b]{2}{*}{$\begin{array}{c}\text { Average Pore Size, } \\
\text { nm }\end{array}$} & \multicolumn{2}{|c|}{ BET Data } & \multirow[b]{2}{*}{$\begin{array}{c}\mathrm{D}_{1}, \mathrm{~cm}^{2} \mathrm{~s}^{-1} \\
\left(\mathrm{M}_{\mathrm{t}} / \mathrm{M}_{\infty}\right)^{2}<0.5\end{array}$} & \multirow[b]{2}{*}{$\begin{array}{c}\mathrm{D}_{2}, \mathrm{~cm}^{2} \mathrm{~s}^{-1} \\
\left(\mathrm{M}_{\mathrm{t}} / \mathrm{M}_{\infty}\right)^{2}>0.5\end{array}$} \\
\hline & & & $\begin{array}{c}\text { Area, } \\
\mathrm{m}^{2} \mathrm{~g}^{-1}\end{array}$ & $\begin{array}{c}\text { Monolayer, } \\
\mathrm{g} \mathrm{g}^{-1}\end{array}$ & & \\
\hline E0 & 0.28 & 3.07 & 1.827 & 0.00052 & $1.68 \times 10^{-8}$ & $5.32 \times 10^{-8}$ \\
\hline E0-75 & 0.29 & 3.83 & 1.519 & 0.00320 & $5.30 \times 10^{-8}$ & $1.24 \times 10^{-7}$ \\
\hline E0-300 & 0.35 & 5.12 & 1.370 & 0.00390 & $5.67 \times 10^{-8}$ & $1.64 \times 10^{-7}$ \\
\hline EP0-600 & 0.52 & 1.19 & 8.782 & 0.00250 & $5.28 \times 10^{-8}$ & $1.26 \times 10^{-7}$ \\
\hline EF5 & 0.88 & 2.10 & 8.416 & 0.00234 & $4.92 \times 10^{-8}$ & $1.27 \times 10^{-7}$ \\
\hline EF5-75 & 0.63 & 2.14 & 5.900 & 0.00168 & $4.59 \times 10^{-8}$ & $1.40 \times 10^{-7}$ \\
\hline EF5-300 & 0.92 & 1.72 & 10.700 & 0.00305 & $4.59 \times 10^{-8}$ & $1.35 \times 10^{-7}$ \\
\hline EF5-600 & 0.48 & 1.11 & 8.680 & 0.00240 & $6.80 \times 10^{-8}$ & $1.32 \times 10^{-7}$ \\
\hline EF15 & 1.48 & 1.56 & 19.050 & 0.00540 & $4.60 \times 10^{-8}$ & $1.30 \times 10^{-7}$ \\
\hline EF15-75 & 1.12 & 1.36 & 16.554 & 0.00471 & $4.29 \times 10^{-8}$ & $1.56 \times 10^{-7}$ \\
\hline EF15-300 & 0.82 & 2.05 & 8.039 & 0.00229 & $4.32 \times 10^{-8}$ & $1.42 \times 10^{-7}$ \\
\hline EF15-600 & 0.96 & 2.08 & 9.280 & 0.00264 & $4.69 \times 10^{-8}$ & $1.59 \times 10^{-7}$ \\
\hline EF20 & 1.51 & 0.72 & 42.090 & 0.00110 & $4.84 \times 10^{-8}$ & $1.05 \times 10^{-7}$ \\
\hline EF20-75 & 3.19 & 2.54 & 25.180 & 0.00730 & $4.54 \times 10^{-8}$ & $1.72 \times 10^{-7}$ \\
\hline EF20-300 & 2.31 & 1.47 & 31.617 & 0.00900 & $4.96 \times 10^{-8}$ & $1.43 \times 10^{-7}$ \\
\hline EF20-600 & 1.47 & 1.60 & 18.430 & 0.00520 & $4.91 \times 10^{-8}$ & $1.47 \times 10^{-7}$ \\
\hline
\end{tabular}
$C$ represents the sorption constant and $p / p_{\mathrm{o}}$ is the relative humidity. The BET model allows one to calculate the surface area in a range of activities from 0.00 to 0.35 . The BET data are summarized in Table 2.

Table 2. Main data evaluated from sorption isotherms and diffusion coefficients.

Assuming cylindrical pore geometry, the average pore size was estimated using the relation (6) [43] (Table 2):

$$
r_{p m}=\frac{2 n}{100 \cdot \rho_{a} \cdot A}
$$


where $r_{p m}$ is the average pore size, $A$ denotes the BET surface area, $n$ is the percentage uptake, $\rho_{a}$ is the solvent phase density.

As was expected, the water absorption in nonirradiated EPDM composites increases as the level of flax fiber increased (Table 2) attaining the highest water uptake of $1.51 \%$ for sample EF20. The increased water uptake could be due to the hydrophilic nature of the flax fibers. As a result, the increase of the $\mathrm{OH}$ groups in samples determines more hydrogen bonds between water molecules and flax fibers leading to a net weight gain of the EPDM/flax composites [44]. Also, for the EPDM composite without flax fiber the sorption capacity increases as the irradiation dose increases (Figure 17a). It was observed for electron beam-treated EPDM/flax composites EF5 and EF 15 that the sorption capacity was lower as compared to the nonirradiated sample (Table 2). The effect of electron beam irradiation was very significant for sample EF5 at $600 \mathrm{kGy}$, when the sorption capacity was found to be $0.48 \%$. The decrease in water uptake with increasing irradiation dose can be determined by the increase of the crosslinking density during irradiation leading to the reduction of the volume required for water molecule diffusion. However, for EPDM/flax composite EF20 the water uptake and the specific surface area are accompanied with an increase of their values regardless of the irradiation dose (Table 2). Generally, the values of diffusion coefficients remain at the same order of magnitude, indicating that irradiation dose does not drastically affect the inner morphology. As expected D2 is one order of magnitude higher that D1 due to long time exposure to water vapor sorption.

\section{Conclusions}

The dielectric parameters such as dielectric constant and dielectric loss monotonically decreased with the increase of frequency, but they become independent as the frequency increased above $10^{3} \mathrm{~Hz}$. The dielectric constant and dielectric loss increased with increasing flax fiber loading due to the increase of the number of polar groups in the composites leading to a higher orientation polarization. Overall, the EPDM/flax composites revealed higher values of dielectric parameters as compared to a pristine sample. The dielectric relaxation behavior of EPDM/flax composites exhibits several relaxation processes as the temperature increases, namely $\beta$-relaxation which corresponds to local motions occurring at lower temperatures and $\alpha, \alpha^{\prime}$-relaxations associated to the cooperative reorientation motions of the polymer segments. The activation energy of the $\alpha^{\prime}$-relaxation was estimated using Vogel-Fulcher-Tammann relation having higher values for electron beam-irradiated samples. The water uptake of EPDM composites was influenced by the flax level and the irradiation dose. The simultaneous analysis of the thermal degradation of the EPDM/flax composites by TG/FTIR/MS technique showed details about the polymer decomposition process. The main gaseous products evolved during the composite degradation were determined. By tuning composition and crosslink density the desired properties of EPDM/flax fiber composites can be achieved in order to be used as polymeric insulators.

Author Contributions: Conceptualization, A.A., M.A. and M.D.S.; formal analysis, investigation, M.D.S., A.B., N.T., N.F., V.M.; methodology, M.A., A.A. and M.D.S.; writing-review and editing, A.A., M.A. and N.F. All authors have read and agreed to the published version of the manuscript.

Funding: This research was funded by the LIFE program in the frame of the LIFE-GREENSHOES 4 ALL, LIFE17ENV/PT/000337 project and by the Romanian Ministry of Research, Innovation and Digitalization through Nucleu Program, PN 191701 03/2019 project (M.D.S.) The APC was funded by LIFE17ENV/PT/00037 project (M.D.S.).

Institutional Review Board Statement: Not applicable.

Informed Consent Statement: Not applicable.

Data Availability Statement: The data that support the findings of this study are available from the corresponding author upon reasonable request.

Acknowledgments: The authors thank to Elena Manaila and Gabriela Craciun for irradiating the EPDM/flax fiber samples with electron beams. 
Conflicts of Interest: The authors declare no conflict of interest.

\section{References}

1. Kim, K.J. Ethylene-propylene-diene terpolymers/silica compound modification with organosilane [bis(triethoxysilylpropyldisulfide] and improved processability and mechanical properties. J. Appl. Polym. Sci. 2010, 116, 237-244. [CrossRef]

2. George, K.; Panda, B.P.; Mohanty, S.; Nayak, S.K. Recent developments in elastomeric heat shielding materials for solid rocket motor casing application for future perspective. Polym. Adv. Technol. 2018, 29, 8-21. [CrossRef]

3. Das, A.; Naskar, N.; Debnath, S.C.; Pal, S.; Dalta, R.N. Effect of vulcanization technique on physical and dielectric properties of black filled EPDM. Kauts. Gummi Kunst. 2005, 58, 304-311.

4. Stelescu, M.D.; Airinei, A.; Manaila, E.; Fifere, N.; Craciun, G.; Varganici, C.; Doroftei, F. Exploring the effect of electron beam irradiation on the properties of some EPDM-flax fiber composites. Polym. Compos. 2019, 40, 315-327. [CrossRef]

5. Stelescu, M.D.; Manaila, E.; Craciun, C. Vulcanization of ethylene-propylene-terpolymer-based rubber mixtures by radiation processing. J. Appl. Polym. Sci. 2013, 128, 2325-2336. [CrossRef]

6. Nihmath, A.; Ramesan, M.T. Preparation, characterization, thermal and electrical properties of chlorinated ethylene propylene diene monomer/hydroxyapatite nanocomposites. Polym. Compos. 2018, 39, 2093-2100. [CrossRef]

7. Colom, X.; Canavate, J.; Formela, K.; Shadman, A.; Saeb, M.R. Assessment of the devulcanization process of EPDM waste from roofing systems by combined thermomechanical/microwave procedures. Polym. Degrad. Stab. 2021, 183, 109450. [CrossRef]

8. Salem, M.A.; Khaled, M.A.; Hussein, A.M. Effect of chromium chloride on the mechanical and dielectric properties of EPDM rubber. Macromol. Res. 2003, 11, 256-259. [CrossRef]

9. Homocianu, M.; Airinei, A.; Stelescu, D.M.; Timpu, D.; Ioanid, A. Morphological structure and surface properties of maleated ethylene propylene diene monomer/organoclay nanocomposites. Polym. Compos. 2012, 33, 379-387. [CrossRef]

10. Natali, M.; Rallini, M.; Puglia, D.; Kenny, J.; Torre, L. EPDM based heat shielding materials for solid rocket motors: A comparative study of different fibrous reinforcements. Polym. Degrad. Stab. 2013, 98, 2131-2139. [CrossRef]

11. Fuke, C.S.; Mahanwar, P.A.; Chowdhury, S.R. Modified ethylene-propylene-diene elastomer (EPDM)—containing silicone rubber/ethylene-propylene-diene elastomer (EPDM blends): Effect composition and electron beam crosslinking on mechanical, heat shrinkability, electrical and morphological properties. J. Appl. Polym. Sci. 2019, 136, 47787. [CrossRef]

12. Manaila, E.; Airinei, A.; Stelescu, M.D.; Sonmez, M.; Alexandrescu, L.; Craciun, G.; Pamfil, D.; Fifere, N.; Varganici, C.D.; Doroftei, F.; et al. Radiation processing and characterization of some ethylene-propylene terpolymer/butyl (halobutyl) rubber/nanosilica composites. Polymers 2020, 12, 2431. [CrossRef]

13. Celette, N.; Stevenson, I.; Davids, L.; Davenas, J.; Seytre, G. Irradiation effects on the relaxation behavior of EPDM elastomers. Polym. Int. 2004, 53, 495-505. [CrossRef]

14. Stelescu, M.D.; Airinei, A.; Mihaila, E.; Craciun, G.; Fifere, N.; Varganici, C. Property correlations for composites based on ethylene propylene diene rubber reinforced with flax fibers. Polym. Test. 2017, 59, 75-83. [CrossRef]

15. Hintze, C.; Shirazi, M.; Wiessner, S.; Talma, A.G.; Heinrich, G.; Noordermeer, J.W.N. Influence of fiber type and coating on the composite properties of EPDM compounds reinforced with short aramid fibers. Rubber Chem. Technol. 2013, 86, 579-590. [CrossRef]

16. Guillot, D.G.; Harvey, A.R. EPDM Rocket Motor Insulation. U.S. Patent 6566420, 20 May 2003.

17. Wang, X.; Zhang, G. PTC effect of carbon fiber filled EPDM rubber composite. J. Mater. Sci. Mater. Electr. 2008, 19, 1105-1108. [CrossRef]

18. Shokr, F.S. Dielectric properties of carbon black loaded EPDM rubber based conductive composites: Effect of curing method. J. Amer. Sci. 2012, 7, 387-397.

19. Khalil, A.M.; El-Nemr, K.F.; Khalaf, A.I. Effect of short polyethylene terephthalate fibers on properties of ethylene-propylene diene rubber composites. J. Polym. Res. 2012, 19, 9883. [CrossRef]

20. Psarras, G.C.; Gatos, K.G.; Karahaliou, P.K.; Georga, S.N.; Krontas, C.A.; Karger-Kocsis, J. Relaxation phenomena in rubber/layered silicate nanocomposites. Express. Polym. Lett. 2007, 1, 837-845. [CrossRef]

21. Khalili, S.M.R.; Farsani, E.E.; Rafiezadih, S. An experimental study on the behavior of PP/EPDM/jute composites in impact tensile and bending loadings. J. Reinf. Plast. Compos. 2011, 30, 1341-1347. [CrossRef]

22. Amin, A.; Kandil, H.; Rabia, A.M.; El-Nashar, D.E.; Ismail, M.N. Enhancing the mechanical and dielectric properties A.M. of EPDM filled with nanosized rice husk powder. Polym. Plast. Technol. Eng. 2018, 57, 1733-1742. [CrossRef]

23. Rozik, N.N.; Abd-El Messieh, S.L.; Yaseen, A.A.; Abd-El-Hafiz, A.S. Dielectric and mechanical properties of natural nanofibersreinforced ethylene propylene diene rubber: Carrot foliage and corn gluten. Polym. Eng. Sci. 2013, 58, 874-881. [CrossRef]

24. Jayamani, E.; Hamdan, S.; Rahman, M.R.; Bakri, M.K.B. Comparative study of dielectric properties of hybrid natural fiber composites. Procedia Eng. 2014, 97, 536-544. [CrossRef]

25. Litvinov, V.M.; Orza, R.A.; Kluppel, M.; Van Duin, M.; Magusin, P.C.M.M. Rubber-filler interactions and network structure in relation to stress-strain behavior of vulcanized carbon black filled EPDM. Macromolecules 2011, 44, 4887-4900. [CrossRef]

26. Mijovic, J. Dielectric spectroscopy of reactive networking-forming polymers. In Broadband Dielectric Spectroscopy; Kremer, F., Schonhals, A., Eds.; Springer: Berlin, Germany, 2003; pp. 349-384.

27. Runt, J.P. Dielectric studies of polymer blends. In Dielectric Spectroscopy of Polymeric Materials. Fundamentals and Applications; Runt, J.P., Fitzgerald, J.J., Eds.; ACS: Washington, DC, USA, 1997; pp. 283-302. 
28. Marin-Genesca, M.; Mujal-Rosas, R.; Garcia-Amoros, J.; Mudarra, M.; Juan, X.R.; Colom Fajula, X. Study of thermal, dielectric, and functional characteristics of an ethylene polyethylene diene monomer blended with end-of-life tire microparticles amounts. Polymers 2021, 13, 509. [CrossRef] [PubMed]

29. Azizi, S.; Momen, G.; Ouellet-Plamondon, C.; David, E. Performance improvement of EPDM and EPDM/silicone rubber composites using modified fumed silica, titanium dioxide and graphene additives. Polym. Test. 2020, 84, 106281. [CrossRef]

30. Abdel-Aziz, M.M.; Atia, M.K.; Amer, H.A.; Rabie, A.M. Physico-mechanical properties of gamma irradiated EPDM rubber nanocomposites loaded with fumed silica and zirconium silicate. Egypt. J. Rad. Sci. Appl. 2015, 28, $169-185$.

31. Li, H.; Liu, F.; Tian, H.; Wang, C.; Guo, Z.; Liu, P.; Peng, Z.; Wang, Q. Synergetic enhancement of mechanical and electrical strength in epoxy/silica nanocomposites via chemically-bonded interface. Compos. Sci. Technol. 2018, 167, 539-546. [CrossRef]

32. Wang, C.; Li, H.; Zhang, H.; Wang, H.; Liu, L.; Xu, Z.; Liu, P.; Peng, Z. Influence of addition of hydroxyl-terminated liquid nitrile rubber on dielectric properties and relaxation behavior of epoxy resin. IEEE Trans. Dielectr. Electr. Insul. 2016, 23, 2258-2269. [CrossRef]

33. Pissis, P.; Apekis, L.; Christodoulides, C.; Niaonakis, M.; Kyritsis, A.; Nedbal, J. Water effects in polyurethane block copolymers. J. Polym. Sci. Part B Polym. Phys. 1996, 34, 1529-1539. [CrossRef]

34. Havriliak, S.; Negami, S. A complex plane representation of dielectric and mechanical relaxation processes in some polymers. Polymer 1967, 8, 161-210. [CrossRef]

35. Gunasekaran, G.S.; Natarajan, R.K.; Kalu, A. FTIR spectra and mechanical strength analysis of some selected rubber derivatives. Spectrochim. Acta Part A Mol. Biomol. Spectrosc. 2007, 68, 323-330. [CrossRef] [PubMed]

36. Litvinov, V.M.; De, P.P. Spectroscopy of Rubbers and Rubbery Materials; RAPRA Technol. Ltd.: Shawbury, UK, 2002.

37. Mustata, F.S.C.; Tudorachi, N.; Mustata, A.; Mustata, F. Physical and thermal characterization of some cellulose fabrics as reinforced materials for composites. J. Thermal. Anal. Calorim. 2015, 120, 1703-1714. [CrossRef]

38. Sing, K.S.W.; Everett, D.H.; Haul, R.A.W.; Moscou, L.; Pierotti, R.A.; Rouquerol, J.; Siemieniewska, T. Reporting physisorption data for gas/solid systems-with special reference to the determination of surface area and porosity. Pure Appl. Chem. 1985, 57, 603-619. [CrossRef]

39. Gujel, A.A.; Bandeira, M.; Menti, C.; Perondi, D.; Guegan, R.; Roesch-Ely, M.; Giovanela, M.; Crespo, J.S. Evaluation of vulcanization nanoactivators with low zinc content: Characterization of zinc oxides, cure, physico-mechanical properties, $\mathrm{Zn}^{2+}$ release in water and cytotoxic effect of EPDM compositions. Polym. Eng. Sci. 2018, 58, 1800-1809. [CrossRef]

40. Crank, J. The Mathematics of Diffusion, 2nd ed.; Clarendon Press: Oxford, UK, 1975.

41. Balik, C.M. On the extraction of diffusion coefficients from gravimetric data for sorption of small molecules by polymer thin films. Macromolecules 1996, 29, 3025-3029. [CrossRef]

42. Brunauer, S.; Deming, L.S.; Deming, W.E.; Teller, E. On a theory of the van der Waals adsorption of gases. J. Am. Chem. Soc. 1940, 62, 1723-1732. [CrossRef]

43. Murray, K.L.; Seaton, N.A.; Day, M.A. An adsorption-based method for the characterization of pore networks containing both mesopores and macropores. Langmuir 1999, 15, 6728-6737. [CrossRef]

44. Chigondo, F.; Shoko, P.; Nyamunda, B.C.; Guyo, U.; Moyo, M. Maize stalk as reinforcement in natural rubber composites. Int. J. Sci. Technol. Res. 2013, 2, 263-271. 